\title{
Laboreal
}

Volume $17 \mathrm{~N}^{\circ} 2$ | 2021

Trabalho e Território

\section{Os impactos da indústria 4.0 no território e nas práticas pedagógicas de formadores/as}

Los impactos de la industria 4.0 en el territorio y en las prácticas pedagógicas de los formadores

Les impacts de l'industrie 4.0 sur le territoire et sur les pratiques pédagogiques des formateurs

The impacts of industry 4.0 on the territory and on the pedagogical practices of trainers

Ana I. Azevedo, João Caramelo e Sofia Marques da Silva

\section{OpenEdition}

\section{Journals}

Edição electrónica

URL: https://journals.openedition.org/laboreal/18410

DOI: $10.4000 /$ laboreal. 18410

ISSN: 1646-5237

\section{Editora}

Universidade do Porto

\section{Refêrencia eletrónica}

Ana I. Azevedo, João Caramelo e Sofia Marques da Silva, «Os impactos da indústria 4.0 no território e nas práticas pedagógicas de formadores/as», Laboreal [Online], Volume 17 N² | 2021, posto online no dia 01 dezembro 2021, consultado o 05 dezembro 2021. URL: http://journals.openedition.org/ laboreal/18410 ; DOI: https://doi.org/10.4000/laboreal.18410

Este documento foi criado de forma automática no dia 5 dezembro 2021

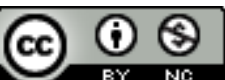

Laboreal está licenciado com uma Licença Creative Commons - Atribuição-NãoComercial 4.0 Internacional. 


\section{Os impactos da indústria 4.0 no território e nas práticas pedagógicas de formadores/as}

Los impactos de la industria 4.0 en el territorio y en las prácticas pedagógicas de los formadores

Les impacts de l'industrie 4.0 sur le territoire et sur les pratiques pédagogiques des formateurs

The impacts of industry 4.0 on the territory and on the pedagogical practices of trainers

Ana I. Azevedo, João Caramelo e Sofia Marques da Silva

\section{NOTA DO EDITOR}

Manuscrito recebido em : 07/06/2021

Aceite após peritagem em : 30/09/2021

\section{Introdução}

O estudo das atividades de trabalho tem sido feito maioritariamente a partir das categorias profissionais ou de atividade sectorial muito mais do que a partir de uma visão de território como categoria principal de análise, ainda que as bases de uma Geografia do Trabalho, enquanto princípio de análise, tenham sido já lançadas nos trabalhos de Pierre George, ao longo de várias das suas obras, sendo uma das mais revelantes "Géographie industrielle du monde", publicada em 1947. Contudo, a evolução industrial e tecnológica, nomeadamente com a convergência das telecomunicações com a informática a partir da década de 70 veio trazer uma nova abordagem ao espaço e uma nova forma sociocultural de o entender na relação simbiótica entre a sociedade, as 
novas tecnologias e a cultura de base microeletrónica, levando a que a interpretação do conceito de espaço, e seus sucedâneos como lugar ou o território, seja influenciada pela crescente interligação mundial dos computadores, que resulta no conceito de ciberespaço, tal como enunciado por Pierre Lévy (1999).

2 Nesta lógica, muito mais do que a importância do território físico geográfico para a análise das atividades do trabalho, são os avanços tecnológicos e a digitalização que assumem especial importância enquanto parte integrante de uma dinâmica evolutiva e contínua das técnicas criadas pelo ser humano (Baudin \& Nusshold, 2018) que permitem antever uma mudança estrutural profunda no mundo do trabalho. Este fenómeno parece ter sido acelerado pela pandemia de COVID-19 que obrigou a um confinamento e distanciamento físicos, ao mesmo tempo que exigiu uma transformação radical na nossa forma de interagirmos e trabalharmos (Dwivedia et al., 2020). Emergiram novos processos e práticas, influenciados por esta obrigatoriedade de distanciamento social e padrões de trabalho alterados. Esta mudança impôs novas formas de trabalho remoto e uma consequente utilização de sistemas digitais de comunicação numa tentativa de adaptação à realidade pandémica. Esta nova realidade tornou visível uma nova forma de conceção do território, como categoria de análise das atividades de trabalho. Algumas atividades económicas não têm o mesmo limite espacial que as atividades políticas ou as comunicações, ao mesmo tempo que cada vez mais se trabalha longe dos locais físicos de trabalho fixos e com um elevado grau de interação com as tecnologias da informação e comunicação, através daquilo que se designa por nomadismo digital.

3 Em 2020, o Fórum Económico Mundial estimava que depois da pandemia de COVID-19, mais de $50 \%$ de trabalhadores/as exerceriam a sua função de uma forma remota e $84 \%$ dos empregadores estariam a trabalhar na digitalização dos processos de trabalho para expandir o trabalho remoto. Adero e Juma (2021) designam esta nova forma de trabalho por remotopia, o fenómeno de trabalhar em casa ou num terceiro espaço que não o local físico de trabalho. Crê-se que existe capacidade para mover $44 \%$ da força de trabalho para operar remotamente (Fórum Económico Mundial, 2020), o que poderá levar a uma mudança nas localizações espaciais dos locais de trabalho levando a uma dispersão de talentos, habilidades, capital produzido e oportunidades através da transformação digital a que assistimos. Simultaneamente, estas transformações poderão também acentuar algumas desigualdades, que serão reproduzidas em ciberterritórios, ou precarizar as condições de trabalho e os direitos dos/as trabalhadores/as.

4 O termo "Indústria 4.0", surge pela primeira vez num artigo publicado pelo governo alemão em novembro de 2011 fazendo parte da High-Tech Strategy 2020 (Zhou, Liu, \& Zhou, 2015), a estratégia alemã no setor dos serviços, fabricação e manufatura e que se tornou pioneira para o que começou a ser apelidado de nova revolução industrial. 0 seu objetivo é o de fortalecer a competitividade do país através da aproximação da produção industrial às tecnologias da informação e comunicação.

5 Não existe formalmente uma definição única para o conceito (Mrugalska \& Wyrwicka, 2017), mas antes a assunção da sua plurissignificação consoante o prisma a partir do qual é analisado. Mais do que um mero conceito, é um novo paradigma tecnológico e industrial que tem na sua génese estratégias capazes de implementar tecnologia de ponta, de digitalização e automação do ambiente de produção, que inclui o design, fabricação, operação e manutenção de sistemas e produtos, onde os processos de 
manufatura passam a estar assentes nestes desenvolvimentos tecnológicos e digitais (Carvalho, 2017), nomeadamente através da implementação de sistemas ciberfísicos inteligentes e interligados, Internet de Coisas (IoT) e Internet de Serviços (IoS), que permitirão a conexão de pessoas, máquinas, equipamentos, sistemas logísticos e produtos, bem como a cooperação entre eles (Roblek et al., 2016).

6 Indústria 4.0 é um termo aplicado a um grupo de rápidas transformações que compreendem uma diversidade de tecnologias que permitem a digitalização e automação da produção industrial, bem como a criação de cadeias de valor digitais (Oesterreich \& Teuteberg, 2016) e um conjunto de tecnologias com capacidade para se integrarem num processo otimizado e automático que muda a relação tradicional entre provedores, produtores e clientes, assim como entre pessoas e máquinas. Refere-se ao desenvolvimento de novas formas de trabalho e novos negócios, numa era impulsionada pela internet em que a digitalização irá atingir todo o tipo de indústrias, sendo esta um pilar na competitividade das mesmas, não apenas nas questões de otimização de processos de produção, mas também em matéria de recursos humanos, seja em termos de literacia digital ou na função que o próprio trabalho cumpre para os sujeitos que o realizam.

7 É importante também realçar que segundo Herman, Pentek, e Otto (2015), é a primeira vez que uma revolução industrial é predita, não sendo apenas observada ex-post, permitindo aos países moldarem as suas estratégias de inserção perante a mesma. É precisamente tendo esta premissa por base que queremos perceber de que modo o

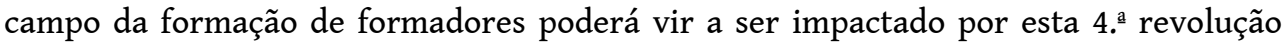
industrial.

Os recentes desenvolvimentos tecnológicos digitais assentes maioritariamente no desenvolvimento contínuo e cada mais aprofundado de tecnologias e de inovações

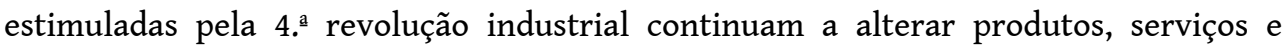
sistemas de produção e exigir profissionais capazes de desenvolver continuamente novos conhecimentos, tendências tecnológicas e competências (Kipper et al., 2021). Este fenómeno digital contínuo, disruptivo e complexo (Spöttl \& Windelbandb, 2021) desafia o campo educativo e a função e a atividade de formador/a e abre as portas a uma nova conceptualização do próprio conceito de território, que deixa de ser apenas físico/ geográfico, para se constituir como digital/virtual, com consequentes mudanças também na prática profissional dos/as formadores/as e na própria formação de formadores.

Partindo dos conceitos de território físico/geográfico e território virtual/digital, da sua ligação aos avanços tecnológicos e aos impactos da $4 .^{a}$ revolução industrial, procuraremos compreender, através da análise de respostas a um inquérito por questionário feito a formadores/as nacionais, quais os impactos percecionados dos desenvolvimentos tecnológicos decorrentes da 4. ${ }^{a}$ revolução industrial no território nacional e na sua atividade. Assim, as questões de investigação a que procuraremos responder são :

1. Qual o impacto do conceito de indústria 4.0 no território português? E a existir, será suficiente para que a variável território se constitua como uma categoria de análise específica?

2. Qual o impacto do conceito de indústria 4.0 na prática pedagógica dos/as formadores/as em contexto industrial? 


\section{Referencial teórico}

\subsection{Do vapor à inteligência artificial : avanços tecnológicos e impactos territoriais das revoluções industriais}

10 O uso de tecnologia por parte dos seres humanos é uma realidade tão antiga como a própria humanidade, nomeadamente através da contínua criação de fenómenos e de artefactos para podemos comunicar e intervir sobre os contextos que habitamos e simultaneamente podermos compreender o mundo.

11 A utilização de tecnologia tem-se intensificado e acelerado nos últimos séculos levando a que desde o século XVIII e que, sensivelmente a cada 100 anos, assistamos a uma nova revolução industrial, cujo processo acaba por ter impacto em praticamente todas as esferas da vida social. Cada revolução industrial permitiu sempre fazer um imenso caminho de avanço tecnológico, fosse com a invenção do motor a vapor e utilização das máquinas no processo de mecanização de algumas indústrias, como na 1. revolução industrial, fosse com a descoberta da energia elétrica e do uso do petróleo e por novos processos de produção na 2. revolução industrial, e é inegável que estes avanços tecnológicos têm tido impacto, quer no território, quer nos modelos de educação e formação.

12 A 1. Revolução Industrial, também chamada de revolução do ferro e do carvão, ocorreu no século XVIII, essencialmente na Europa e Estados Unidos da América, com a invenção do motor a vapor e utilização das máquinas no processo de mecanização de algumas indústrias, sendo a mais relevante a indústria têxtil. Simultaneamente, a invenção do comboio como principal meio de locomoção, permitiu não só mecanizar processos que antigamente eram totalmente artesanais e torná-los mais céleres, como também mover mercadorias e pessoas de forma mais rápida e por distâncias cada vez mais longas. Do ponto de vista económico, isso significou produzir maior quantidade de produto em menos tempo e de forma mais económica. Consequentemente, para os cidadãos significou a possibilidade de adquirir bens que lhes dariam conforto e um melhor nível de vida e melhorar o padrão médio de vida e o crescimento do rendimento médio das famílias (Carvalho, 2017). Simultaneamente, conduziu ao aumento das estruturas das cidades onde estes cidadãos passaram a residir em maior número, à criação de novas leis destinadas à sociedade industrial e também à aquisição de novas competências por parte dos/as trabalhadores/as.

13 A 2. Revolução Industrial ocorreu entre meados do século XIX e inícios do século XX, com especial ênfase nos Estados Unidos, Japão, Alemanha e França, sendo marcada pela descoberta da energia elétrica e do uso do petróleo e por novos processos de produção, que permitiram a produção em massa do aço e do alumínio e o crescente número de ferrovias que foram construídas na época levando a uma maior conexão do mundo (Mokyr, 1998), à exploração de novos mercados e à aceleração do ritmo industrial. Do ponto de vista económico, a produção continua a ser célere e a qualidade dos produtos aumenta, enquanto simultaneamente são inventados o telégrafo e mais tarde o telefone, a televisão, o rádio, o automóvel e posteriormente o avião, que irão mudar a nossa conceção de distâncias. Há um investimento massivo na elaboração de máquinas capazes de reduzir os custos e o tempo de fabricação dos produtos, passando as máquinas a funcionar com maior automação, o que significava que a quantidade de trabalho necessário a ser feito pelas pessoas diminui (Mokyr, 1998). Este modelo 
revolucionou a indústria automóvel a partir de 1914, quando Henry Ford introduziu a primeira linha de montagem automatizada, seguindo os princípios de padronização e simplificação de Frederick Taylor, que visavam melhorar a eficiência e a eficácia operacional de uma empresa levando a um maior lucro (Mokyr, 1998), consolidando o capitalismo e acelerando a economia mundial e permitindo-nos uma deslocação territorial muito mais facilitada e com uma substancial redução do tempo empregue nesta. É também nesta altura, que se debate os empregos técnicos e os não qualificados e se tenta medir o desempenho do trabalhador e o seu rendimento em função do seu conhecimento, quando se analisa o impacto da máquina a vapor na demanda de novas competências na indústria de navegação mercante (Chin, Juhn, \& Thompson, 2006).

É com a 3. Revolução Industrial, também conhecida por revolução técnico-científica e da informação ou revolução digital que acontece já no século XX, por volta de 1960 até aos dias atuais, que se dá a incorporação das tecnologias digitais nos processos industriais, fazendo uso dos computadores inicialmente e posteriormente da internet (Carvalho, 2017). Outro aspeto central desta 3.a revolução industrial é a descentralização territorial, que passa a estar assente não apenas na questão dos transportes aéreos que se democratizam e passam a permitir o transporte massivo de pessoas e mercadorias, mas também nas comunicações, através de satélites, da internet e das ligações de dados, cada vez mais velozes, que permitem a integração simultânea de informações em diferentes locais. Estes dois fatores, em simultâneo, permitem que as indústrias passem a estar localizadas em regiões economicamente mais vantajosas, geralmente com mão-de-obra mais barata, com matérias-primas acessíveis e abundantes e um amplo mercado de consumidores, como o caso da China ou da Índia, países cuja economia se desenvolveu em grande escala, graças à deslocalização de grandes multinacionais. Esta terceira fase do processo de industrialização foi decisiva para consolidar o capitalismo e a divisão internacional do trabalho, também conhecida por globalização que aconteceu em definitivo no final do século XX com a utilização mais democratizada e massiva da internet que mudou, em definitivo, o conceito de distância.

Se as duas primeiras revoluções industriais tiveram como principal impacto a redução da escassez de produtos que melhorariam a longevidade, como alimentos, roupas e cuidados de saúde, a 3. revolução permitiu melhorar a qualidade de vida de uma maneira nova (Greenwood, 1999). Graças à democratização da internet, a população a nova possibilidade de expandir os seus conhecimentos e de divulgar as suas ideias e a sua cultura, de uma forma antes considerada impossível (Carvalho, 2017). Do ponto de vista económico, o modelo fordista-taylorista é substituído pelo modelo Toyotista, assente em práticas de melhoria contínua em que a produção é flexibilizada de acordo com a procura, exigindo mais e melhor tecnologia e, consequentemente, um menor número de trabalhadores/as que, por sua vez, devem ser cada vez mais competentes na operação de sistemas de produção mais complexos e sofisticados.

Atualmente, vivemos num tempo em que a $4{ }^{a}$ revolução industrial já está em curso, havendo uma interligação entre os mundos digital e real através do uso do smartphone ou do computador, permitindo uma conectividade entre dispositivos e sistemas de informação, dado os primeiros passos da chamada Internet das Coisas (IoT), progressivamente a ser incorporada na indústria e nos processos de manufatura, nomeadamente através da automação da produção. O desenvolvimento de sistemas ciberfísicos (CPS) que monitorizam e tomam as decisões, fazendo com que os produtos 
estejam "conscientes" da sua história de produção, do seu estado atual, do resultado esperado e das várias opções até esse término, torna os produtos em agentes ativos que podem decidir como devem ser fabricados, graças aos sistemas informáticos que permitem a comunicação entre máquinas e produtos (Carvalho, 2017).

\subsection{O território ciberfísico : a interligação do território físico e do território digital}

17 A conceção do território pode ser abordada sob múltiplas perspetivas de análise. Neste artigo focar-nos-emos especificamente em duas perspetivas, que se revelam fundamentais para compreender as mudanças da chamada $4{ }^{a}$ revolução industrial, bem como os seus impactos no campo da formação profissional, e simultaneamente as mudanças trazidas pela pandemia de COVID-19:

i. Território físico/geográfico, termo com raiz no Império Romano, entendido como regiões e lugares, circundados por fronteiras políticas e juridicamente individualizados (Cataia, 2011), mas cujo significado moderno, enquanto área de exercício do poder de um Estado emerge e cristaliza no século XVII, "quando Estado e soberania passam a compor uma única ordem territorial e as fronteiras que circunscrevem cada território passam a ser respeitadas internacionalmente" (Cataia, 2011, p. 116)., enquanto as interferências nos assuntos internos de um país passam a ser reconhecidas como violação dos direitos internacionais Daqui surgem as primeiras fronteiras modernas que demarcam os primeiros Estados-territoriais do mundo (Cataia, 2011).

ii. Território virtual/digital, também chamado de ciberespaço por Pierre Lévy (1999), um conceito de território que emerge da interligação mundial dos computadores e que abrange a infraestrutura material, a quantidade de informações que a comunicação digital abriga e os humanos que navegam, habitam e se alimentam desse universo ; ou cyberia na designação de Stuart (1998), uma realidade simulada que é em si mesma uma simulação, e que vem marcar o fim da geografia e tornar a internet um domínio supergeográfico e as indústrias de telecomunicações uma nação.

18 Se tivermos em conta que a $4 .^{\text {a }}$ revolução industrial será primariamente feita nas instalações físicas das indústrias presentes num determinado território geográfico, mas totalmente assente em desenvolvimentos tecnológicos e tecnologias digitais que virtualizam o conceito de território, compreenderemos a centralidade destes dois conceitos na análise que apresentamos neste artigo.

Estamos num momento em que já não basta definir o conceito de território físico e geográfico e o conceito de território virtual ou digital, é preciso compreender a interligação e sobreposição dos dois, naquilo que afeta em simultâneo estas duas realidades : a física e a virtual e por isso denominamos este território como ciberfísico, categoria onde as mudanças atravessam simultaneamente o território físico e o virtual, ao mesmo tempo que transportam impactos de uma realidade para a outra.

20 A 4. revolução industrial afetará estas duas realidades, criando uma complexidade maior e sendo ainda difícil antever de que forma cada mudança numa realidade e na outra, irá impactar-se mutuamente, mas sabendo de antemão que as duas se cruzam e interligam. À semelhança dos sistemas ciberfísicos (CPS), na génese da 4. a revolução industrial e compostos por elementos computacionais colaborativos com o intuito de controlar entidades físicas onde o papel das ligações entre os elementos computacionais e os elementos físicos é de especial importância, também o território se torna ciberfísico, ou seja o território virtual, digital ou ciberespaço determina as 
mudanças que acontecem no território físico ou geográfico e no papel do Estado enquanto entidade garante de soberania territorial.

\subsection{A formação de formadores em Portugal}

21 Atualmente, e face a esta 4. ${ }^{\mathrm{a}}$ revolução industrial, acreditamos ser imperativo voltar a olhar para o papel da formação de formadores, não apenas na qualificação $\mathrm{e}$ requalificação de trabalhadores/as que operam na indústria, mas de forma quase transversal a todas as áreas, tendo em conta os desenvolvimentos tecnológicos a que assistimos, de modo a proporcionar às pessoas e às empresas as novas competências de que necessitam e virão a necessitar. Para isso, importa compreender de forma mais detalhada qual o percurso e contexto histórico que a formação de formadores percorreu até aos dias de hoje.

mortugal, a formação de formadores assenta no pressuposto de que a mesma contribui para a qualidade da formação profissional, das suas práticas e dos seus resultados e, como tal, "exige uma atuação que promova a capacidade técnica e pedagógica dos respetivos formadores, através do reforço permanente das suas competências" (Portaria n. 214/2011). Isto acontecerá através da valorização da certificação da aptidão pedagógica do formador, estimulando a mobilização das competências capazes de induzir uma relação pedagógica eficaz em diferentes contextos de aprendizagem. Também a obrigatoriedade da formação pedagógica inicial para o acesso à atividade de formador, garantindo uma intervenção qualificada neste domínio e da promoção da formação contínua dos/as formadores/as, salientando a necessidade da sua atualização permanente, em especial daqueles que intervêm em ações dirigidas a públicos mais desfavorecidos pretende-se reforçar a qualidade da formação profissional (Portaria n.․ 214/2011). Todos estes objetivos elencados contribuem para reforçar a visão de que a formação de formadores se encontra ao serviço de uma formação profissional que acontece maioritariamente nos locais de trabalho e não nos sistemas de ensino formal (Fontes, 2002).

O sistema de formação de formadores, no âmbito da formação profissional é relativamente recente, sendo de 2011 o diploma que estabelece o regime da formação e certificação de competências pedagógicas dos/as formadores/as que desenvolvem a sua atividade no âmbito do Sistema Nacional de Qualificações (SNQ). Inicialmente, a formação de formadores limitou-se a uma simples importação da Formação Profissional Acelerada, desenvolvida em França nos anos trinta e importada por Portugal nos anos sessenta, com o objetivo de formar rapidamente operários destinados a executarem atividades pouco complexas (Fontes, 2002). Na mesma altura dá-se a criação do Centro Nacional de Formação de Monitores (CNFM) em 1965, essencialmente destinado à preparação de pessoal em serviço nos centros de formação profissional, com um carácter essencialmente instrumental e centrado na otimização do desempenho dos mesmos (Rodrigues, 2019 ; Lopes, 2006). À sua semelhança, a formação dos primeiros formadores de formadores foi também realizada em França no mesmo ano e ao abrigo de um protocolo como Institut Nactional de Formation Professionelle (INFP) (Fontes, 2002), demonstrando o forte impacto francófono que se mantém ainda hoje nesta área.

A revolução do 25 de Abril cria um no marco neste sistema, não apenas com a queda do regime, mas também com todos os impactos que a mesma teve na população e no tecido económico português. Em 1978 é criada a Unidade de Formação na Empresa, cujo 
objetivo era apoiar as empresas na formação dos seus colaboradores e que acabou também por ter um papel importante na promoção da formação de formadores (Almeida, 2002), com a introdução de novas temáticas, como o diagnóstico de necessidades de formação, a comunicação e a motivação, bem como de outros métodos, tais como a autoscopia (Rodrigues, 2019 ; Lopes, 2006). Em 1979 é criado o Instituto do Emprego e Formação Profissional (IEFP) com o objetivo de integrar num único organismo a execução das políticas de emprego e formação profissional. Ao longo dos anos 70 assiste-se à diluição das barreiras entre educação, formação e trabalho e a uma reflexão estratégica sobre a temática da formação profissional, na sua relação com os subsistemas com os quais interage, designadamente os do emprego onde os programas de promoção deste envolvem a realização de ações de formação (Fontes, 2002).

Os anos 80 trazem consigo a abertura do país ao exterior através da colaboração com organizações internacionais, como a OIT e a UNESCO, introduzindo temáticas e técnicas novas na formação de formadores (Fontes, 2002). Simultaneamente os centros protocolares, que resultam de acordos entre o IEFP e associações sectoriais, contribuem para o desenvolvimento de metodologias próprias de formação, dada a sua autonomia, nomeadamente em termos pedagógicos (Fontes, 2002). Em 1982 surge o Centro Pedagógico do IEFP com a criação de um Núcleo de Produção de Recursos Didáticos, que viria a ser a Divisão de Recursos Didáticos do Centro Nacional de Formação de Formadores (CNFF), criado em 1985 com o objetivo de "programar, desenvolver e avaliar as ações de formação de formadores nas suas componentes técnica e pedagógica" (Portaria 656/86). O CNFF "passa a ser concebido como um verdadeiro instituto politécnico, onde seria assegurada a qualificação e o aperfeiçoamento de todos os agentes de formação, não apenas no domínio pedagógico, mas também técnico" (Fontes, 2002, p. 52), realizando ações de formação dirigidas aos vários agentes de formação que atuavam no terreno, nomeadamente cursos de formador de formadores em 1989 e 1990, (Fontes, 2002). A adesão de Portugal à Comunidade Económica Europeia em 1986 permitiu o acesso a meios financeiros consideráveis para a realização de atividades de formação, no âmbito do Fundo Social Europeu (FSE), que levou ao aumento exponencial das ações de formação ministradas fora do sistema regular de ensino (Almeida, 2002). A partir de 1987, o CNFF promove o Programa da Aprendizagem, que definiu um programa para a formação pedagógica inicial de formadores, mantendo uma lógica de formação modular, com percursos formativos flexíveis que permitiam a individualização da formação e conteúdos mais especializados. Estas medidas levaram à normalização e sistematização de conteúdos $\mathrm{e}$ duração da formação que se manteve até 2007 e que influenciou a evolução do próprio sistema de formação de formadores (Fontes, 2002).

A década de 90 veio trazer um investimento significativo ao nível da formação de formadores, através da criação do Centro Nacional de Formação de Formadores (CNFF) e da realização do 1. Encontro Nacional de Formação de Formadores, em 1989 (Rodrigues, 2019). Simultaneamente a formação de formadores passa a organizar-se de forma modular, ao mesmo tempo que se discute a urgência da implementação das novas tecnologias de informação e comunicação neste âmbito (Fontes, 2002). É também nesta altura que é constituída uma bolsa de formadores de formadores e se inicia o processo de certificação dos mesmos (Almeida, 2002). Contudo, a dissolução e reativação sucessiva do CNFF, entre 1991 e 1996, evidencia a indefinição de rumo que se vivia em matérias de formação de formadores (Rodrigues, 2019 ; Almeida, 2002). A isto junta-se a precaridade dos vínculos laborais, em que "a maioria dos formadores exerce 
a atividade como alternativa ao desemprego ou como complemento remuneratório de uma outra atividade principal" (Fontes, 2002, p. 69) e a precaridade de ofertas de formação de formadores, já que estas eram escassas. Só a partir de 1997 é que se torna obrigatório o recurso a formadores certificados, nas ações de formação financiadas pelo Fundo Social Europeu (FSE), e se estabelecem normas específicas respeitantes à certificação e às condições de homologação da formação necessária à obtenção do Certificado de Aptidão Profissional (CAP) de Formador. Simultaneamente definem-se as condições de renovação do mesmo (Rodrigues, 2019) com a definição de conteúdos e a duração mínima exigida para esta formação (Fontes, 2002). É também neste ano que se dá a criação do Centro Nacional de Qualificação de Formadores (CNQF), uma unidade orgânica do IEFP, com a missão de aumentar a qualidade da formação profissional através da formação pedagógica dos/as formadores/as (Rodrigues, 2019). No ano seguinte é publicado o Referencial Básico para a Formação Pedagógica Inicial de Formadores que veio a tornar-se o modelo-padrão de formação de formadores (Fontes, 2002).

27 A partir dos anos 2000, o número de entidades que promoviam cursos de formação de formadores, aumentou de forma exponencial, assim como os certificados emitidos, com uma oferta igual à sugerida no referido referencial, sem qualquer tipo de especialização e não tendo em conta o distrito nem a implantação dos diferentes sectores de atividade (Fontes, 2002). Surge também nesta altura a necessidade de renovação dos certificados de formadores, através de cursos previamente aprovados pelo IEFP de Formação Pedagógica Contínua de Formadores, com uma duração de 60 horas ou 300 horas de formação comprovada.

A partir de 2010 o antigo CAP e atual CCP deixa de ter prazo de validade, independentemente dos/as formadores/as terem ou não feito algum tipo de processo de aprendizagem e/ou atualização. No entanto, continua a existir um referencial de Formação Contínua de Formadores e que especializa estes profissionais para a formação de formadores, mantendo-se a necessidade permanente de reforço das competências do formador definidas no Decreto-Lei 396/2007, de 31 de dezembro, mas cuja aplicação e execução ficam omissas no quadro legal que regula a formação e certificação de competências pedagógicas dos/as formadores/as (Portaria n.․ 214/2011, de 30 de maio). É também em 2011 que é estabelecido o regime da formação e certificação de competências pedagógicas dos/as formadores/as, aplicável a qualquer pessoa que exerça a atividade de formador e que seja titular do Certificado de Competências Pedagógicas (СCP), obtido através da frequência com aproveitamento, de um curso de Formação Pedagógica Inicial de Formadores (FPIF), por equivalência atribuída a determinados cursos superiores (como é o caso da Licenciatura em Ciências da Educação), por via da docência (uma vez que todos os professores estão isentos do CCP) ou por via do Reconhecimento, Validação e Certificação de Competências (RVCC) (Portaria n.. 214/2011). Os cursos de Formação Pedagógica Inicial de Formadores podem ser ministrados por entidades formadoras certificadas pelo IEFP, I.P., estando os mesmos suportados num referencial base e organizados de forma modular, com uma duração total de referência de 90 horas. Após conclusão com aproveitamento do mesmo, é emitido automaticamente e por via eletrónica o CCP.

29 Na perspetiva do legislador, a formação de formadores obedece a uma lógica de promoção da qualidade da formação com o objetivo de melhorar as práticas e os resultados obtidos nas ações de formação profissional, desenvolvendo as competências 
das entidades formadoras e dos seus/suas formadores/as (Resolução do Conselho de Ministros n.. 173/2007). A melhoria da qualificação dos/as formadores/as apontada na Reforma da Formação Profissional surge como um mecanismo eficaz de constante adaptação e aperfeiçoamento aos novos referenciais e necessidades e no sentido de garantir o reforço da qualidade das respostas formativas. A formação profissional contínua assume a centralidade de todo o processo formativo como a sustentação dos processos de desenvolvimento competitivo e de promoção da coesão social (Almeida, 2002), onde a formação de formadores assume um papel secundário de suporte a este mesmo objetivo. Deste modo, é impossível tentar compreender o fenómeno da formação de formadores, sem ter sempre presente a própria formação profissional e o modo como esta condiciona toda a temática da própria formação de formadores. Esta está ao serviço de uma lógica de qualidade da formação profissional, onde os/as formadores/as dotados de competências técnicas, tentam dominar as competências pedagógicas a fim de melhorarem a qualidade do processo formativo. Por sua vez, a formação profissional em Portugal está intimamente ligada às questões do trabalho $\mathrm{e}$ do emprego, sendo por isso impossível analisar esta temática da formação de formadores, sem ter em conta todas estas questões da qual formação de formadores deriva numa primeira instância.

Assim se verifica que a Formação de Formadores é considerada um instrumento de desenvolvimento estratégico, consubstanciado na política de educação e formação e nas agendas e planos de políticas públicas atuais (IEFP, 2010), sendo a qualidade da formação profissional afetada pela qualificação dos/as próprios/as formadores/as (Fontes, 2002) e como tal, esta adquire uma especial relevância devido à importância crescente da formação profissional, intimamente associada em termos políticos à preocupação com a qualificação do capital humano na construção da Europa e com as novas formas de utilização dos recursos humanos no sistema económico (CEDEFOP, 1999). Aqui, a formação profissional é vista como é um processo de desenvolvimento global dos indivíduos e da sociedade, no âmbito da educação de adultos, onde a formação para a cidadania e para a mudança social são igual e amplamente mente valorizadas.

\subsection{Pandemia, Teletrabalho \& Formação à Distância}

31 A pandemia de COVID-19 em Portugal que nos atingiu em março de 2020 levou à obrigatoriedade do teletrabalho, que se tem mantido de forma intermitente desde essa data até agora (set.21), tendo por base também o risco epidemiológico de cada concelho. Esta medida já estava prevista nos artigos $165^{\circ}$ a $171^{\circ}$ do Código de Trabalho Português (Lei n. ${ }^{\circ}$ 7/2009, de 12 de fevereiro), definida como a prestação laboral realizada com subordinação jurídica, habitualmente fora da empresa e através do recurso a tecnologias de informação e de comunicação.

Não obstante, a realidade laboral, decorrente do dever de confinamento para toda a população portuguesa, é nova para a maioria dos/as trabalhadores/as, e especialmente para a maioria daqueles que exercem a atividade de formador/a, já que os únicos dados disponíveis indicam que a oferta de e-Learning das entidades formadoras, representava, no máximo, $10 \%$ relativamente à oferta presencial para formandos dispersos ao nível nacional. 

(OIT) no documento "Home Work Convention", Recomendação n. 177, onde "o termo trabalho em casa significa o trabalho realizado por uma pessoa, designada como trabalhador/a em casa, (i) na sua casa ou em outro local à sua escolha, que não o local de trabalho do empregador ; (ii) remunerado ; (iii) que resulta num produto ou serviço conforme especificado pelo empregador, independentemente de quem fornece o equipamento, materiais ou outros inputs utilizados, a menos que esta pessoa tenha o grau de autonomia e de independência económica necessária para ser considerada um/ a trabalhador/a independente de acordo com as leis, regulamentos ou tribunais nacionais". Tal convenção e recomendação pretendeu estabelecer normas de aplicação geral, relativas às condições de trabalho aplicáveis aos/às trabalhadores/as em casa, tendo em conta as condições particulares e as características especiais que caracterizam o trabalho em casa. estava o conflito entre trabalho e responsabilidades familiares, uma questão social e política urgente em muitos países durante a última parte do século XX (Hein, 2005) e que perdura até aos dias de hoje, onde o conflito de ganhar um sustento decente para a família e, ao mesmo tempo, garantir o cuidado dos dependentes apresenta, muitas vezes, problemas insuperáveis, especialmente para as famílias de baixos rendimentos. Em 2005, a Organização Internacional do Trabalho (OIT) atualiza o conceito para "um acordo de trabalho em que os funcionários podem realizar as suas responsabilidades de trabalho num local diferente do local de trabalho do empregador, muitas vezes, embora não necessariamente, em casa. $O$ teletrabalho também pode ocorrer no escritório de um cliente, num escritório satélite num centro de teletrabalho. Alguns teletrabalhadores/ as podem trabalhar apenas de casa, enquanto outros podem trabalhar em casa apenas algumas vezes ou numa base de emergência" (Hein, 2005, p. 153).

Neste pressuposto consideramos que a atividade profissional dos/as formadores/as transitou para um regime de teletrabalho, nomeadamente através da Formação à Distância, ou designado a nível europeu, como ensino aberto e à distância (Open and Distance Learning - ODL), entendido como um processo onde o formando não dispõe de outras estruturas além de um computador com acesso à Internet e sendo este o equipamento essencial de acesso a e estruturas humanas e materiais, ou designado a nível europeu.

A Formação à Distância em Portugal é primeiramente definida no Despacho n. $\mathrm{e}$ 17035/2001, de 14 de agosto de 2001, como "um método de formação com reduzida intervenção presencial do formador, em que se recorre à utilização de materiais didáticos diversos, em suportes escrito, áudio, vídeo, informático ou multimédia, com vista não só à aquisição de conhecimentos como também à avaliação do progresso do formando".

Historicamente, a Formação à Distância tem-se desenvolvido sempre em torno das revoluções tecnológicas, fazendo com que haja uma imensa expectativa sobre a forma como cada tecnologia pode operar uma revolução no sector da educação (Cação \& Dias, 2003). Se a 1.a Revolução Industrial, permitiu o ensino por correspondência com o desenvolvimento dos serviços postais a 2. Revolução Industrial permitiu a aplicação de filmes, vídeos e da televisão à aprendizagem, de onde se destaca a iniciativa da Telescola em Portugal. Já a 3. ${ }^{a}$ Revolução Industrial, com a democratização da internet, abriu o ciclo que vivemos atualmente não apenas com a possibilidade do e-learning,

Laboreal, Volume $17 \mathrm{~N}^{\circ} 2$ | 2021 
entendido como a formação à distância via internet, mas também com a facilidade com que se encontram conteúdos e tutoriais na web (Cação \& Dias, 2003).

Vivendo atualmente uma pandemia com períodos prolongados de confinamento, que exigiram e ainda exigem em a suspensão de muitas interações pessoas e sociais não será de estranhar a ampla adoção de tecnologias digitais, quer em questões de trabalho, quer na nossa vida pessoal, fazendo com que plataformas como o Zoom ou o Teams se tenham incorporado no nosso léxico diário (Dwivedia et al, 2020) e tenham servido objetivos educativos e formativos. Não será, pois, de estranhar, um uso intenso da expressão "formação à distância" no vocabulário de todos os profissionais de ensinoaprendizagem.

Tendo em conta todas as considerações apresentadas anteriormente propomo-nos a tentar compreender quais os impactos da 4. ${ }^{a}$ Revolução Industrial no território nacional e simultaneamente na prática pedagógica dos/as formadores/as. Posteriormente, pretendemos compreender se esses impactos justificam que a variável território se constitua como uma categoria de análise por si mesma. Contudo, a nossa análise parte de uma conceção de território nova, o território ciberfísico, uma intersecção entre o território físico/geográfico e o território virtual/digital, e da forma como a 4 . revolução Industrial poderá impactar cada um deles individualmente e em simultâneo.

\section{Método}

o presente artigo é parte integrante de uma investigação científica de doutoramento [1], cujo objetivo geral é compreender quais as transformações, desafios e impactos desta 4. ${ }^{a}$ revolução industrial na formação de formadores/as em Portugal e contribuir para o desenvolvimento de um novo referencial pedagógico, baseado nas competências de futuro necessárias à Indústria 4.0. Neste artigo esperamos antecipar quais os conhecimentos e competências necessárias aos/às formadores/as que atuam em áreas relacionadas com a indústria 4.0 e compreender qual a importância do território na sua atuação profissional, trazendo novamente para a discussão a necessidade de considerar a implantação dos diferentes sectores de atividade nestes (Fontes, 2002).

41 Propomo-nos assim : 1) caracterizar detalhadamente o tecido industrial em Portugal por distrito e por código de atividade económica (CAE) das empresas, realizada entre março de 2019 e outubro de 2020 ; e 2) analisar os dados obtidos através de um inquérito por questionário realizado aos/às formadores/as de todo o território nacional, recolhidos entre dezembro de 2020 e abril de 2021. Não sendo o questionário diretamente dedicado à situação pandémica e seus impactos vivenciados em 2020, a verdade é que o mesmo foi preenchido pelos/as formadores/as durante grande parte do período do 2. confinamento no país, permitindo-nos, desse modo, estabelecer algumas relações entre esta realidade e a realidade da formação profissional em Portugal.

42 Para a caracterização do tecido industrial português foram identificadas todas as empresas nacionais, organizadas por tipologia de atividade económica e por distrito. Esta sistematização fez-se a partir do site RACIUS (https://www.racius.com/ empresas/), que fornece um conjunto de dados sobre empresas, bem como serviços de alerta de criação de empresas ou exportação de bases dados à medida. No caso, todos os dados foram verificados de forma a garantir a qualidade e veracidade dos mesmos. 

compreender quais destas empresas seriam efetivamente consideradas indústria e consequentemente fariam parte da nossa amostra. Tivemos por base a publicação "Estatísticas da Produção Industrial 2019", de dezembro de 2020, onde foram divulgados os principais resultados da produção industrial portuguesa em 2019, obtidos a partir do Inquérito Anual à Produção Industrial (IAPI). Nesta publicação, a produção industrial é caraterizada tendo por base metodologias e listas de produtos harmonizadas, no âmbito da União Europeia, de acordo com o Regulamento (CEE) no 3924/91, de 19 de dezembro de 1991 e o Regulamento (CE) no 912/2004, de 29 de abril de 2004. as portugueses/as composto por 30 perguntas ou afirmações escritas às quais os sujeitos respondem, permitindo por isso a recolha de dados em extensão, o que foi nosso objetivo, dado o âmbito geográfico alargado que pretendíamos atingir. 0 referido questionário tem por objetivo : (i) caracterizar a realidade e os contextos de atuação dos/as formadores/as nacionais; (ii) aferir o conhecimento sobre o conceito de indústria 4.0 ; (iii) conhecer as mudanças realizadas na prática pedagógica tendo em conta esta $4 .{ }^{\circ}$ revolução industrial; (iv) auscultar a necessidade de atualização do referencial de formação inicial de formadores ; e (v) antecipar quais os conhecimentos e competências necessárias aos/às formadores/as que atuam em áreas relacionadas com a indústria 4.0. Este questionário pretende fornecer dados que fundamentem a importância e pertinência de um novo referencial de formação pedagógica de formadores face a um conjunto de conhecimentos e competências que acreditamos serem necessários mobilizar nesta nova revolução industrial, já que é um dos objetivos do projeto de Doutoramento no qual se insere.

O questionário é composto por 23 perguntas fechadas e 7 perguntas de resposta aberta. A primeira parte (perguntas 1 a 7) pretende caracterizar os respondentes do questionário, nomeadamente género, idade, habilitações literárias, distrito onde exerce atividade habitualmente, regime em que exerce a atividade de formador (freelance ou formador/a interno/a), área em que exerce atividade e tipologia de indústria para a qual habitualmente desenvolve formação. A segunda parte (perguntas 8 a 13) pretende aferir o grau de conhecimento sobre o conceito de indústria 4.0 e de nativos digitais, através de perguntas abertas e fechadas sobre os referidos conceitos. A terceira parte (perguntas 14 a 18) tem com o objetivo detalhar o grau de familiaridade com o conceito de indústria 4.0, procurando avaliar a frequência ou a concretização de ações de formação sobre esta temática, as aéreas específicas em que tal se faz decorrentes das áreas identificadas pelo Fórum Económico Mundial (2020) e as mudanças efetuadas na prática pedagógica decorrentes da familiaridade com o conceito. A quarta parte (perguntas 19 a 30) procura avaliar as perceções sobre as competências essenciais para o futuro dos/as trabalhadores/as (Fórum Económico Mundial, 2016), a necessidade de atualização do referencial de formação inicial de formadores, as áreas de conhecimento técnico e transversal necessárias à atividade de formador/a (a partir de áreas previamente identificadas na literatura) e os módulos do referencial de formação de formadores para os quais se reconheça a maior necessidade de aquisição e/ou atualização e conhecimentos.

Laboreal, Volume 17 N²2 | 2021 

práticas pedagógicas dos/as formadores/as portugueses/as, iremos apenas analisar as perguntas que constituem a terceira parte do questionário :

- Pergunta fechada 14 : "Já frequentou ações de formação no âmbito da indústria 4.0 ?"

- Pergunta fechada 15 : "Já ministrou ações de formação no âmbito da indústria 4.0 ?"

-Pergunta fechada 16 : "Se sim, em que áreas ? Escolha todas as que considere aplicáveis."

- Pergunta fechada 17 : “As alterações associadas à i4.0 já conduziram à necessidade de efetuar mudanças na sua prática pedagógica?”

- Pergunta aberta 18 : "Quais as mudanças efetuadas na sua prática pedagógica associadas ao conceito de indústria 4.0 ?".

O inquérito por questionário foi enviado através de email, não apenas em virtude do período de confinamento, mas principalmente porque a investigação em educação reconhece as possibilidades que a Internet oferece no recrutamento de participantes e no facto dos inquéritos por questionário online terem vindo a proliferar nos últimos anos. Para isso, foram contactas via email : 1) entidades formadoras portuguesas ; 2) escolas de formação profissional, que posteriormente fizeram chegar o questionário aos/às seus/suas formadores/as e 3) formadores/as inscritos/as na mailing list da Base de dados Netforce do Instituto de Emprego e Formação Profissional (IEFP). No contacto feito via email era indicado um link para o questionário, sem a identificação de nenhum dado pessoal e respeitando todas as premissas do Regulamento Geral sobre a Proteção de Dados (RGPD).

nossa população é composta por 350.000 formadores/as certificados/as e isentos/as de CCP (Certificado de Competências Pedagógicas) inscritos na Bolsa Nacional de Formadores (Netforce) nas 77 áreas de educação e formação. Contámos com o apoio do Instituto de Emprego e Formação Profissional (IEFP), que faz a gestão da referida Base de Dados Netforce.

A amostra é composta por um conjunto de 1586 respostas válidas, com um grau de confiança de $95 \%$ e uma margem de erro de $5 \%$. Esta amostra é composta por $63,7 \%$ indivíduos do género feminino $(\mathrm{n}=1.010)$ e $36,1 \%$ indivíduos do género masculino $(\mathrm{n}=$ 573). A maioria destes indivíduos (32,9\%) situa-se na faixa etária dos $36-45$ anos, possui licenciatura como nível de escolaridade ( $46 \%$ e são formadores/as freelancer (61\%). As áreas de formação indicadas no inquérito foram selecionadas tendo por base as 47 Áreas de Educação e Formação do Catálogo Nacional de Qualificações da Agência Nacional para a Qualificação e o Ensino Profissional, I.P. sendo que poderiam ser selecionadas todas as que fossem aplicáveis. Da análise concluímos que as áreas com mais formadores/as a ministrar formação são : 345. Gestão e Administração $(n=229)$, 729. Saúde - Programas não Classificados noutra Área de Formação $(n=202)$ e 347. Enquadramento na Organização/Empresa $(n=159)$. Na distribuição geográfica, verificamos que a maioria habitualmente realiza formação em Lisboa $(31,1 \%)$, Porto (21,1 \%) e Setúbal (5,6 \%).

O conteúdo das respostas abertas foi analisado recorrendo a análise de conteúdo, descrevendo-o e organizando-o em categorias de significação, permitindo a realização de inferências lógicas e explicitamente fundamentadas sobre essas mensagens (Bardin, 2011). A análise foi realizada indutivamente, com a construção de categorias emergentes, a partir das perceções e representações dos/as formadores/as.

Laboreal, Volume 17 №2 | 2021 
51 É de salientar que o questionário foi disseminado para toda a base de dados nacional de formadores (350.000) do Instituto de Emprego e Formação Profissional (IEFP) numa época em que vivíamos o segundo confinamento da pandemia de COVID-19.

\section{Resultados e Análise}

\subsection{Territórios portugueses mais industrializados}

A caracterização do tecido empresarial português, permitiu compreender que este é vasto e integra um total de 586.818 empresas distribuídas por 88 Códigos de Atividade Económica (CAE) com 3 dígitos e 850 sub-CAE'S com 5 dígitos, conforme se apresenta no Gráfico 1. Distribuição de Empresas por Código de Atividade económica (CAE).

Nesta análise destacam-se as Atividade Económicas : 47. Comércio a retalho, com um total de 68.854 empresas registadas ; 46. Comércio por grosso, com um total de 49.265 empresas registadas; 41. Promoção imobiliária, com um total de 43.886 empresas registadas, como as que representam o maior número de empresas registadas. Registase também que as Atividade Económicas : 05. Hulha e lenhite - extração e 98. Bens e serviços para uso próprio, apesar de terem um Código atribuído não há registo de nenhuma empresa aberta em Portugal.

No que diz respeito ao tecido industrial português, este é constituído por um total de 62.081 indústrias, distribuídas por 26 Códigos de Atividade Económica (CAE), com uma distribuição por distrito que se apresenta na Tabela 2.

Desde logo compreende-se que o número de indústrias em Portugal corresponde apenas a $11,7 \%$ do total de empresas do país, sendo uma percentagem baixa para este sector face ao total, mas estando em linha com a média europeia, que era de 9,9\% em 2018 (PORDATA, 2020).

Gráfico 1 : Distribuição de empresas por Código de Atividade Económica (CAE)

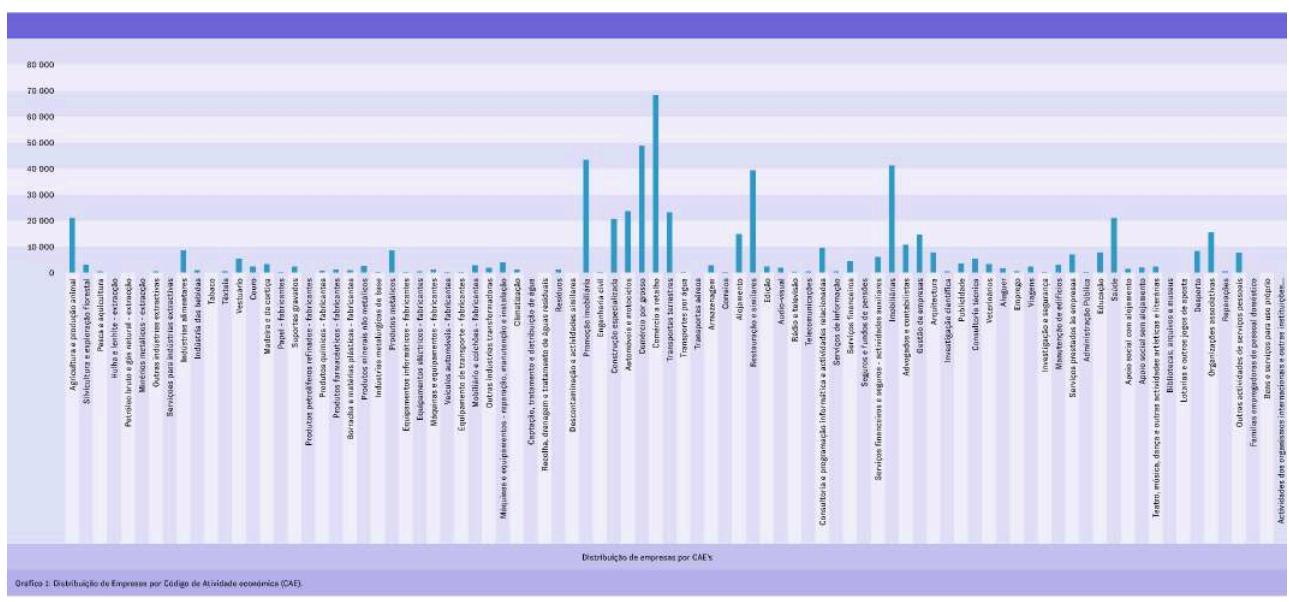

Gráfico 1 : Distribuição de empresas por Código de Atividade Económica (CAE) 
Tabela 1 : Distribuição das indústrias por Código de Atividade Económica (CAE) e distrito

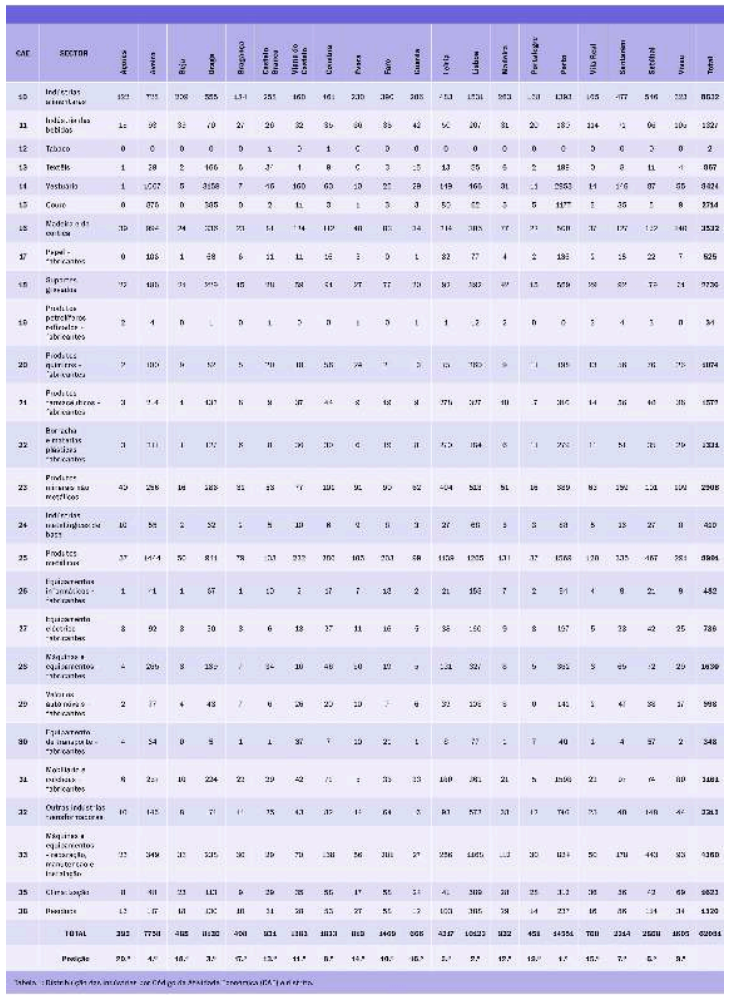

Tabela 1 : Distribuição das indústrias por Código de Atividade Económica (CAE) e distrito

A partir desta distribuição percebemos que as indústrias mais representativas em Portugal são: 25. Produtos metálicos (8.991); 10. Indústrias alimentares (8.852), 14. Vestuário (8.424), 33. Máquinas e equipamentos - reparação, manutenção e instalação (4.360) e 16. Madeira e Cortiça (3.532). Estes dois últimos setores industriais conseguem atingir mais ou menos metade do número dos anteriores, em termos de representatividade.

Por seu turno, as indústrias menos representadas no país são: 12. Tabaco (2); 19. Produtos petrolíferos refinados - fabricantes (34), 30. Equipamento de transporte fabricantes (348), 26. Equipamentos informáticos - fabricantes (482) e 17. Papel fabricantes (525).

Relativamente à variável território, verifica-se que os distritos [ $\left.{ }^{2}\right]$ mais fortemente industrializados são Porto (14.551), Lisboa (10.123), Braga (8.130), Aveiro (7.758) e Leiria (4.217). Por outro lado, os distritos com menos tecido industrial encontram-se na Região Autónoma dos Açores [3] (395), Portalegre (451) e Beja (488). Se agregarmos todos os 6 distritos da Região Norte (Braga, Porto, Viana do Castelo, Aveiro, Vila Real e Bragança) vemos que estes representam um total de $53,12 \%(n=32.980)$ de todas as indústrias portuguesas.

Quando cruzamos as indústrias mais representativas com os distritos onde estão mais representadas, verificamos que na sua maioria são quase sempre os mesmos que destacam : Lisboa, Porto, Aveiro, Braga, Leiria, Setúbal e Viana do Castelo. 
Tabela 2 : Distribuição das indústrias mais representativas pelos distritos onde estão mais representadas

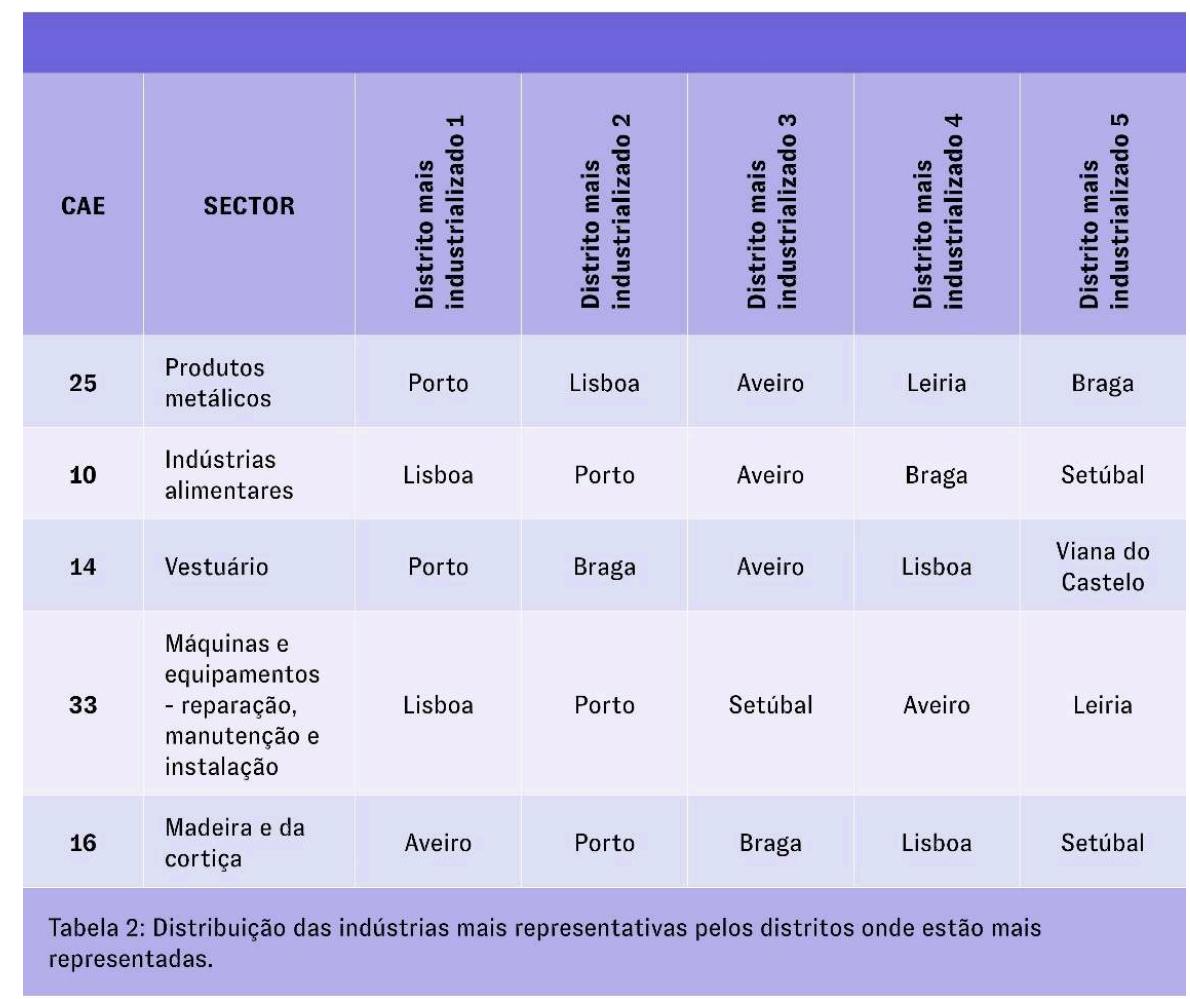

Tabela 2 : Distribuição das indústrias mais representativas pelos distritos onde estão mais representadas

\subsection{Mudanças nas práticas pedagógicas dos/as formadores/as nacionais}

60 A análise das mudanças nas práticas pedagógicas dos/as formadores/as nacionais pretendeu aferir se as mesmas se devem às mudanças introduzidas pelos avanços tecnológicos decorrentes da $4 .{ }^{\text {a }}$ Revolução industrial.

61 Para isso, começamos por perguntar aos/às formadores/as se tinham frequentado ações de formação no âmbito da indústria 4.0 (pergunta 14), tendo concluído que $89 \%$ ( $n=1413)$ nunca frequentou ações de formação neste âmbito e apenas $11 \%(n=173)$ responderam já ter frequentado, sendo a predominância destes nos distritos de Lisboa $(3,9 \%)$, Porto $(2,5 \%)$ e Braga $(0,6 \%)$. 
Tabela 3 : Distribuição por distrito dos/as formadores/as que frequentaram ações de formação no âmbito da i4.0

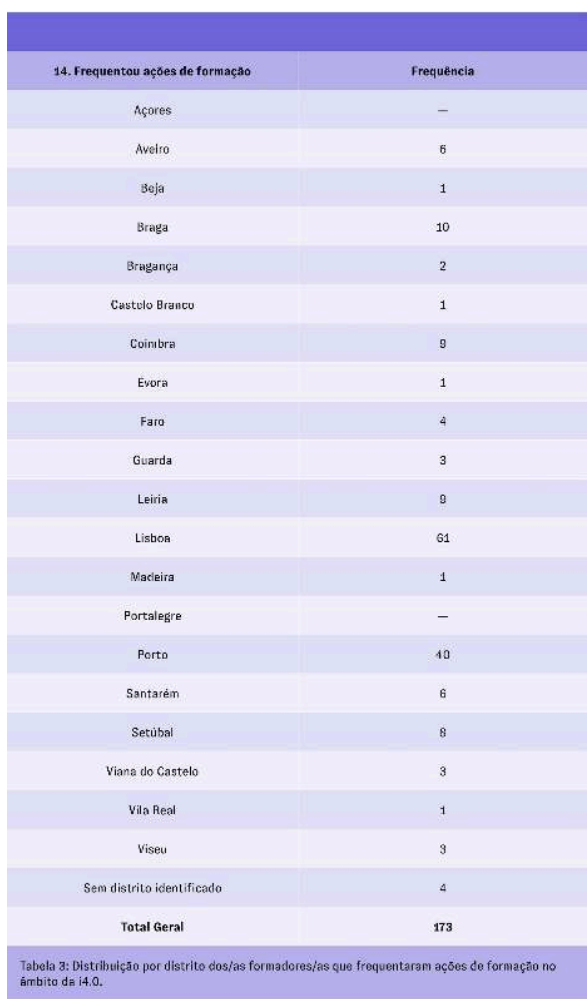

Tabela 3 : Distribuição por distrito dos/as formadores/as que frequentaram ações de formação no âmbito da i4.0

Quando os/as questionamos sobre o facto de já terem sido formadores em ações de formação no âmbito da indústria 4.0 (pergunta 15), obtemos resultados semelhantes. Apenas $1.5 \%(n=24)$ já o fez, contra 87,5\% $(n=1388)$ que nunca desenvolveu formação neste âmbito. Os restantes $11 \%(\mathrm{n}=174)$ não responderam a esta questão. Novamente, encontramos os distritos de Lisboa com maior predominância $(45,8 \%)$, seguidos do Porto (12,5 \%) e Leiria (12,5\%). 
Tabela 4 : Distribuição por distrito dos/as formadores/as que ministraram ações de formação no âmbito da i4.0

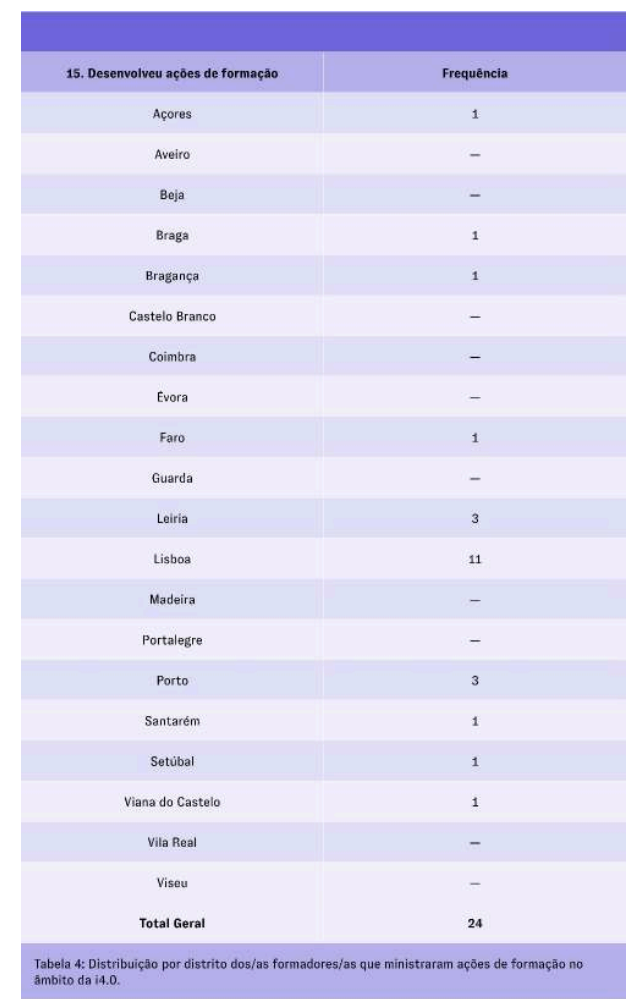

Tabela 4 : Distribuição por distrito dos/as formadores/as que ministraram ações de formação no âmbito da i4.0

63 As áreas de formação frequentadas e/ou desenvolvidas como formador dentro do âmbito da indústria 4.0 (pergunta 16) são maioritariamente Trabalho em Equipa/ Colaborativo (7,48 \%), Gestão de Pessoas (6,89 \%), Inteligência Emocional (6,89 \%), sendo estas três áreas mais ligadas às competências transversais e Internet das Coisas (IoT) \& Internet dos Serviços (IoS) (6,7 \%) e Cibersegurança $(6,41 \%)$ duas áreas mais ligadas às questões de operacionalização técnica da indústria 4.0. 
Tabela 5 : Distribuição dos/as formadores/as pelas áreas de formação da indústria 4.0 frequentadas e desenvolvidas

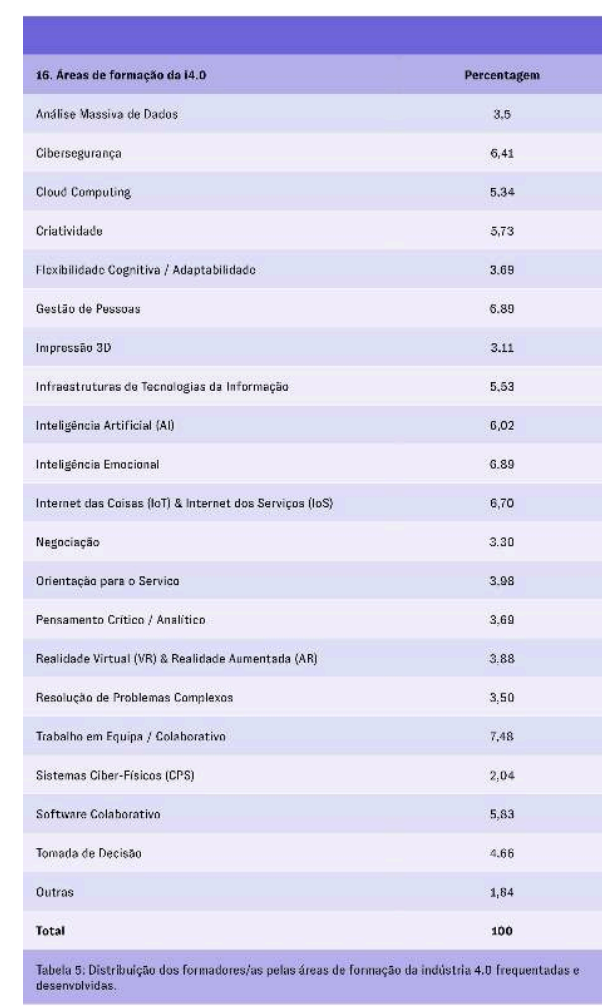

Tabela 5 : Distribuição dos/as formadores/as pelas áreas de formação da indústria 4.0 frequentadas e desenvolvidas

64 Quando analisamos especificamente as respostas às duas perguntas relacionadas com as mudanças na prática pedagógica: pergunta 17 “As alterações associadas à i4.0 já conduziram à necessidade de efetuar mudanças na sua prática pedagógica ?", $9.4 \%$ (n= 149) indicam que sim, $3 \%(n=4$ 8) indicam que Não, e os restantes $87,4 \%(n=1389)$ não respondem à questão. Dos/as 149 formadores/as que responderam afirmativamente a esta pergunta, $60 \%(n=89)$ são do género feminino e $40 \%(n=60)$ do género masculino, o que são valores muito próximos e coincidentes com a amostra total. A sua maioria situa-se na faixa etária dos 36-45 anos (31\%) e 46-55 anos (40\%), possui licenciatura ( $40 \%$ ) ou mestrado (38\%) como escolaridade, são formadores/as freelancer (52\%) e habitualmente desenvolvem formação nos distritos de Lisboa (35\%), Porto (22\%), Leiria (6\%) e Braga (6\%). 
Tabela 6 : Distribuição das mudanças na prática pedagógica por distrito

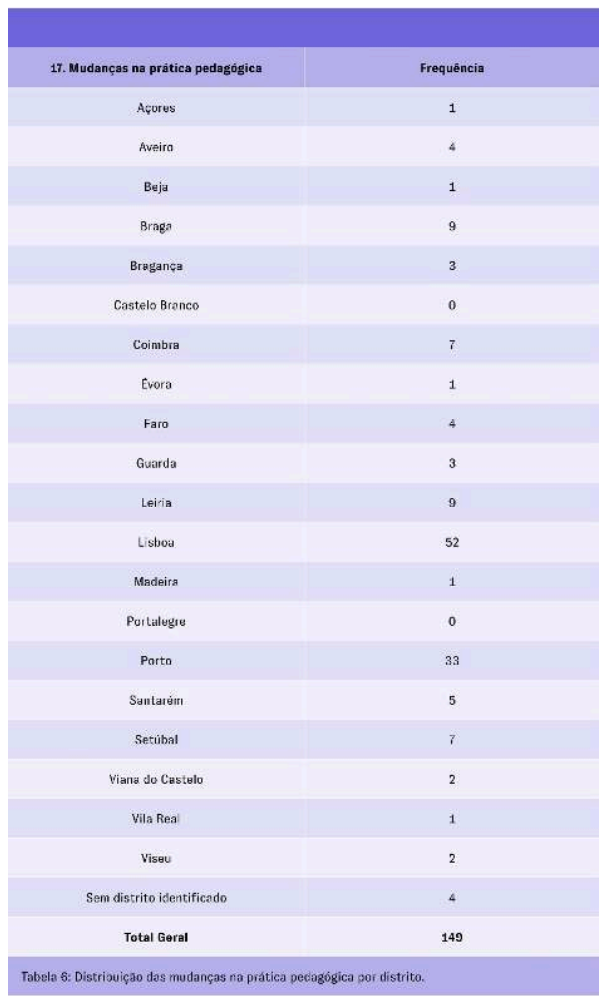

Tabela 6 : Distribuição das mudanças na prática pedagógica por distrito

65 Na pergunta 18 "Quais a mudanças efetuadas na sua prática pedagógica associadas ao conceito de indústria 4.0 ?" verificamos que apenas 119 formadores/as detalharam especificamente que mudanças efetuaram. Da análise de conteúdos e categorização das respostas à pergunta aberta, identificamos maioritariamente 6 grandes categorias emergentes, (e apresentamos entre parêntesis as respetivas frequências) : Competências (9) ; Formação à Distância (67) ; Formador (13) ; Formando (20) ; Novas Metodologias (18) e Novas Tecnologias (53). Algumas das respostas dadas pelos/as formadores/as eram bastante mais detalhadas, permitindo a emergência de 30 subcategorias, organizadas pelas 6 categoria principais, como se pode verificar na Tabela 7. Principais mudanças na prática pedagógica. 
Tabela 7 : Principais mudanças na prática pedagógica

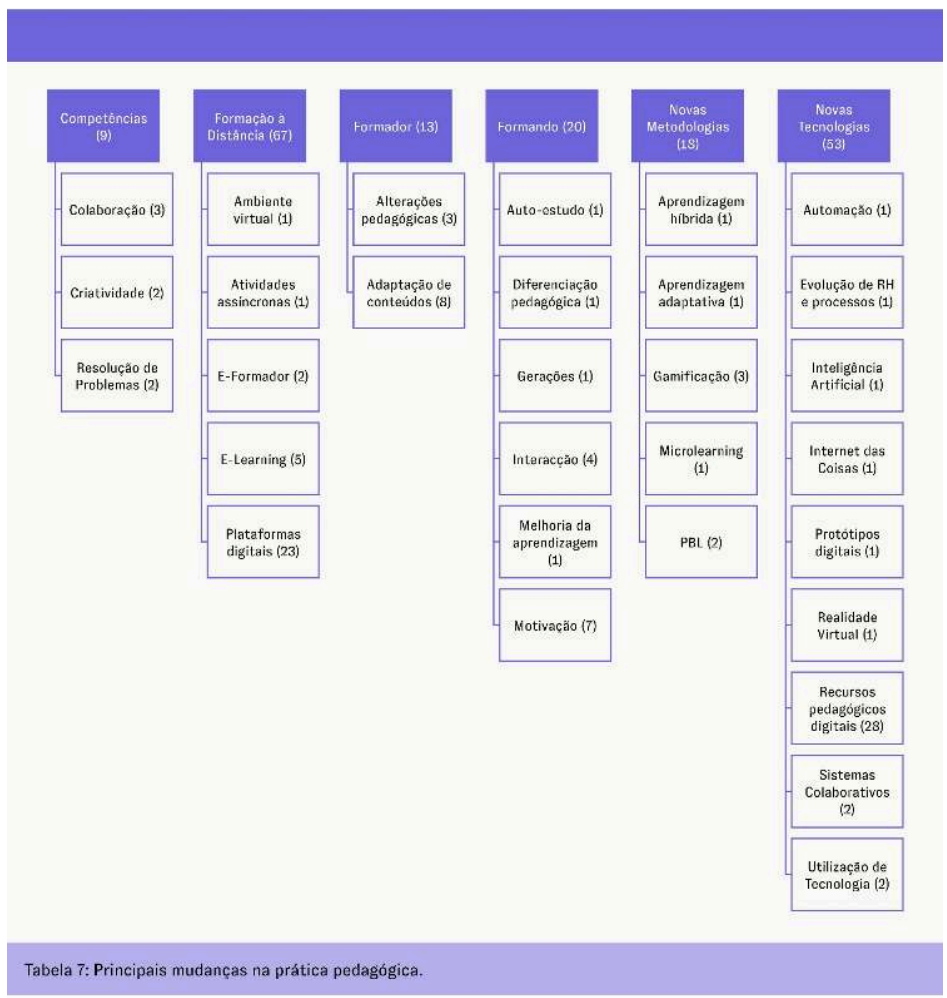

Tabela 7 : Principais mudanças na prática pedagógica

Quando cruzamos estas respostas com a variável território (distrito), verificamos novamente que é nos distritos de Lisboa $(n=69)$ e Porto $(n=69)$ que mais mudanças se reconhecem como tendo sido necessárias aos/as formadores/as, nomeadamente nas áreas de Formação à Distância (Lisboa : 23 e Porto : 18) e Novas Tecnologias (Lisboa : 21 e Porto : 14). De seguida, é o distrito de Braga que mais se destaca com 12 formadores/ as a indicarem mudanças na sua prática pedagógica, sendo a categoria da Formação à Distância a mais relevante (6). 
Tabela 8 : Especificação das mudanças na prática pedagógica por distrito e categoria de análise

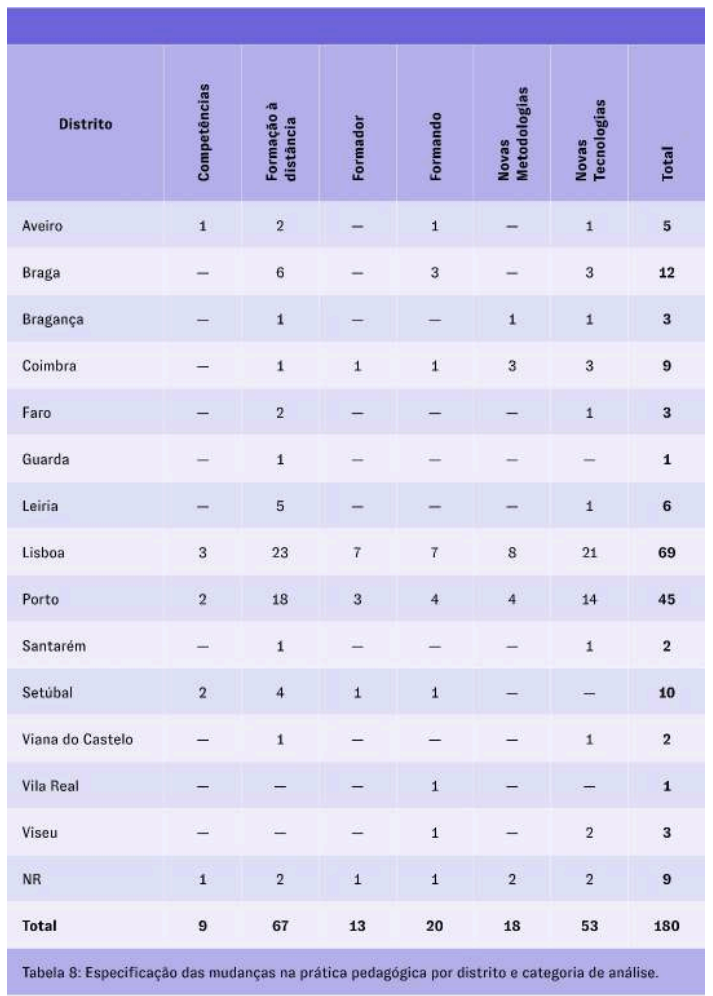

Tabela 8 : Especificação das mudanças na prática pedagógica por distrito e categoria de análise

67 Ao analisarmos concomitantemente as variáveis anteriormente apresentadas, verificamos que há uma quase constante entre territórios (distritos) que ocupam os lugares cimeiros do "N. de indústrias", "Exercício de atividades de formador/a", "Mudanças na prática pedagógica" e "Especificação das mudanças na prática pedagógica" : Lisboa, Porto, Braga, Setúbal, Leiria [ $\left.{ }^{4}\right]$. 


\begin{tabular}{|c|c|c|c|c|c|c|}
\hline Critérios de Análise & 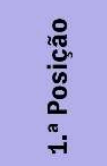 & 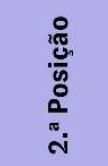 & 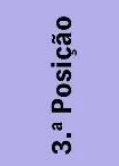 & 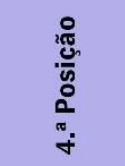 & 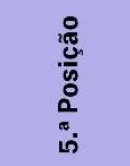 & 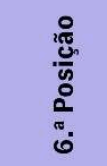 \\
\hline N.o de Indústrias & Porto & Lisboa & Braga & Aveiro & Leiria & Setúbal \\
\hline $\begin{array}{l}\text { Exercício da } \\
\text { Atividade de } \\
\text { Formador/a }\end{array}$ & Lisboa & Porto & Setúbal & Braga & Aveiro & Leiria \\
\hline $\begin{array}{l}\text { Mudanças na prática } \\
\text { pedagógica }\end{array}$ & Lisboa & Porto & $\begin{array}{l}\text { Braga } \\
\text { Leiria }\end{array}$ & - & $\begin{array}{l}\text { Coimbra } \\
\text { Setúbal }\end{array}$ & - \\
\hline $\begin{array}{l}\text { Especificação das } \\
\text { mudanças na prática } \\
\text { pedagógica }\end{array}$ & Lisboa & Porto & Braga & Setúbal & Coimbra & Aveiro \\
\hline
\end{tabular}

Tabela 9 : Posicionamento do território (distrito( face a critérios de análise

\section{Discussão}

\subsection{As mudanças decorrentes da $4 .{ }^{\text {a }}$ Revolução Industrial}

A distribuição das indústrias em Portugal é bastante desigual se tivermos em conta os territórios (distritos) e a tipologia de atividade económica onde se inserem. A distribuição desigual destas indústrias pelo território nacional, privilegia os distritos litorais (Porto, Lisboa, Braga, Aveiro, Leiria, Setúbal) sobre os distritos do interior do país. Estas desigualdades permitem antever, desde já, impactos que serão necessariamente distintos, nos vários níveis, nomeadamente no desenvolvimento socioeconómico e na necessidade de atualização de competências por parte dos/as trabalhadores/as futuramente, bem como no dos conteúdos e estrutura da própria formação necessária a esta atualização.

Apesar de Portugal ser um país pouco industrializado (11,7\%) face ao número de empresas que estavam registadas no país até ao final do ano passado (2020), a verdade é que quando analisamos os números totais e temos em conta os dados dos últimos censos Portugueses (INE, 2011) verificamos que em média para cada 18 cidadãos portugueses há 1 empresa portuguesa de algum tipo de atividade económica, o que de alguma forma se pode explicar pelo facto de $96 \%$ das empresas em Portugal serem microempresas (PORDATA, 2019), ou seja empresas com menos de 10 trabalhadores/as. Tendo também este dado em conta, importa perceber que não haverá com certeza apenas um modelo único de formação destes/as trabalhadores/as. Se as grandes indústrias podem - e algumas já o fazem - desenvolver uma Learning Factory (Fábrica 
de Aprendizagem), um modelo de fábrica real para fins de educação e formação com vista ao desenvolvimento de competências (Kipper et al., 2021), não podemos esperar que as micro indústrias o consigam fazer. Será precisamente aí que a integração entre indústrias/empresas, e instituições de educação e formação, como as universidades e os politécnicos será fundamental para reformular currículos e preparar os/as trabalhadores/as do futuro (Kipper et al., 2021).

70 Ainda que não haja dados detalhados sobre o número de trabalhadores/as por Código de Atividade Económica das indústrias em Portugal, os dados disponíveis apontam para $24,8 \%$ do número de trabalhadores/as no sector secundário e $17,3 \%$ de trabalhadores nas indústrias transformadoras e extrativas (PORDATA, 2021). Estes dados são importantes porque nos permitem antever a percentagem de trabalhadores/as portugueses/as que terá uma necessidade de adquirir ou atualizar as competências face aos desenvolvimentos da digitalização, entendida como uma transformação radical do trabalho na sua representação e realização (Leduc \& Ponge, 2018).

Os dados disponíveis (PORDATA, 2021) apontam para cerca de 833.900 trabalhadores/as apenas nas indústrias extrativas e transformadoras. Embora esta necessidade de aquisição e/ou atualização de competências não seja exclusiva da indústria, a verdade é que sento sendo este sector de atividade económica o que mais impactos imediatos irá sofrer, tendo por base os desenvolvimentos tecnológicos que lhe estão inerentes a nesta 4. revolução industrial, será aquela onde estas necessidades se farão sentir em primeiro lugar. Esta questão assume uma importância fundamental se tivermos em conta a importância estratégica do sector da educação e formação profissional para o desenvolvimento industrial e para o emprego (Spöttl \& Windelband, 2021).

Como vimos, cada revolução industrial gerou uma imensa transformação na perceção do território físico e geográfico, culminando nesta mudança de perceção deste território mais físico para um mais virtual e digital. É aqui que a $4^{\mathrm{a}}$ revolução industrial ganha um maior peso, já que assenta num, cada vez maior, potencial de digitalização tecnológica e globalização, tornando as tecnologias de informação e de comunicação num pilar fundamental desta nova revolução industrial e obscurecendo as fronteiras entre as esferas física, digital e biológica (Fórum Económico Mundial, 2020), provocando impactos ainda difíceis de antever por completo.

73 Esta $4^{\mathrm{a}}$ Revolução Industrial é um dos desenvolvimentos tecnológicos e socioeconómicos mais discutidos atualmente e com impactos profundos na agenda das políticas e estratégias educativas e de formação profissional, a nível mundial. Contudo, verificamos uma quase ausência de foco sobre as implicações atuais e potenciais desta revolução industrial nos sistemas de educação e formação (Spöttl \& Windelbandb, 2021), não havendo conhecimento suficiente sobre as suas consequências (Oke \& Fernandes, 2020). O que nos permite perceber como estamos de facto a ignorar os impactos da indústria 4.0 não apenas na indústria em si, mas também nos sistemas de educação e formação, ainda que uma força de trabalho altamente qualificada tenha sido e continue a ser um fator chave para o sucesso de empresas e países ao longos dos tempos.

O impacto da digitalização é uma discussão que ainda está na sua fase embrionária, os estudos adquiridos sobre as mudanças nas tarefas de trabalho e nos perfis de competência, tendo em conta a cada vez maior digitalização dos processos de produção são ainda escassos e limitados (Spöttl \& Windelbandb, 2021). Para a maioria dos/as trabalhadores/as, os efeitos desta não são visíveis, muito embora o número de 
empresas que administra a sua atividade tendo por base a digitalização seja cada vez maior (Spöttl \& Windelbandb, 2021), levando por isso a presumir que o impacto será também ele maior e crescente no tempo e na complexidade.

Para podermos refletir sobre os impactos na formação de formadores em Portugal, partimos dos impactos desta 4. ${ }^{\mathrm{a}}$ revolução industrial nas competências necessárias ao mercado de trabalho, com o objetivo de melhorar a função atual e a requalificação com o objetivo de aprender um conjunto de competências novas para a novas funções profissionais, nos seguintes aspetos :

i. em questões de literacia digital dos/as trabalhadores/as ;

ii. na mudança na organização e nos processos de trabalho através da automação contínua e do controle em tempo real nas tecnologias aplicadas, nas tarefas realizadas, e na organização do trabalho, entre outros fatores ;

iii. no aumento das necessidades de novas competências e promoção de atualizações de qualificações (Spöttl \& Windelbandb, 2021);

iv. nas necessidades de atualização de competências.

\subsection{A indústria 4.0 como fator potenciador e utilizador da Formação à Distância}

Se o impacto da indústria 4.0 na própria indústria ainda está na fase inicial, não será por isso de estranhar que este mesmo impacto não esteja ainda espelhado em matéria de formação de formadores a nível nacional. Teremos necessariamente de partir destes impactos para os/as trabalhadores/as para podemos pensar e tentar antever alguns dos impactos nos/as próprios/as formadores/as.

77 Assim, partimos do estudo de Oke e Fernandes (2020) que aponta também para uma relação simbiótica entre o setor de educação e as inovações tecnológicas, para refletir e compreender quais os impactos destas transformações na atividade profissional dos/as formadores/as e consequentemente no seu próprio processo de formação. Mais uma vez verificamos que este processo é ainda incipiente no país, na medida em que a percentagem de formadores/as que frequentou ações de formação no âmbito da indústria 4.0 é extremamente baixo ( $11 \%$ ), e ainda mais baixo o número de formadores/as que desenvolveu ações de formação no âmbito da indústria 4.0 (1,5\%). 0 que nos permite de facto concluir que o impacto desta $4 .^{\circ}$ revolução industrial na realidade de formação em Portugal é ainda reduzido. No entanto, não é pela inexistência de impactos mensuráveis e efetivos que podemos deixar de antever as mudanças que se aproxima e que estão amplamente esplanadas na literatura.

No campo da formação de formadores, a indústria 4.0 parece desempenhar um papel de facilitador da experiência de aprendizagem dos aprendentes, nomeadamente contribuindo para um crescimento e desenvolvimento da Formação à Distância, enquanto simultaneamente transforma o local de trabalho e melhora a experiência dos aprendentes. Na nossa investigação verificamos também uma distribuição desigual da atividade dos/as formadores/as, semelhante e na mesma direção da distribuição das indústrias no território nacional. o que se explica efetivamente também pelo facto de haver uma distribuição da população muito semelhante, o que torna Portugal um país bastante desigual neste aspeto, com $44,5 \%$ da população a residir em áreas predominantemente urbanas e concentrando-se sobretudo nos municípios da faixa litoral entre Viana do Castelo e Setúbal e em alguns municípios do litoral algarvio. 

as mudanças nas práticas pedagógicas dos/as formadores/as continuam a acompanhar a mesma tendência de distribuição, mas é um claro sinal de alerta para a indústria portuguesa, que será a principal afetada pelas transformações decorrentes do desenvolvimento tecnológico e da digitalização. Especialmente se tivermos em conta a ausência dos restantes distritos da região norte no que diz respeito às mudanças nas práticas pedagógicas dos/as formadores/as, dado que estes representam mais de metade do n.. total de indústrias no país, mas tal facto pode ser explicado pela deslocação geográfica dos/as trabalhadores/as - formandos/as a outro distrito para receber formação, explicando por que motivo estes não têm uma expressão muito significativa nos critérios "Exercício de atividades de formador/a" e consequentemente no critério "Mudanças na prática pedagógica".

mo exigualdade pode, no entanto, ser explicada e também colmatada de algum modo pela questão da Formação à Distância e das Novas Tecnologias que são efetivamente as duas categorias mais relevantes que emergem da análise de dados no que diz respeito às principais mudanças efetuadas na prática pedagógica destes/as formadores/as. Apesar de não termos perguntas diretamente aos/às formadores/as estas principais mudanças foram, também elas, fruto da situação pandémica que vivíamos quando a investigação foi feita, dado que o questionário foi elaborado e distribuído muito antes de estarmos a viver a pandemia, a recolha das respostas dos/as formadores/as aconteceu em grande medida já em período de confinamento, e por isso acreditamos que estas categorias emergiram como uma forma de ultrapassar as limitações do confinamento e isolamento presencial.

81

udo, ao contrário do que Moreira et al. (2020) referem sobre esta situação de ensino remoto emergencial para os níveis de ensino obrigatórios, onde a maioria das tecnologias seria utilizada numa perspetiva meramente instrumental e as metodologias e as práticas seriam reduzidas a um ensino apenas transmissivo, as conclusões que obtemos demonstram uma Formação à Distância num modelo de educação e formação de adultos sólida, onde a "automação, a "inteligência artificial, os "protótipos digitais", a "realidade virtual" e os "sistemas colaborativos", são algumas das subcategorias referidas na grande categoria das "Novas Tecnologias", demonstrando que estas são muito mais fruto efetivo da revolução industrial a que assistimos do que do momento de situação pandémica que vivenciámos. De forma semelhante verificamos que a "aprendizagem híbrida", a "aprendizagem adaptativa", a "gamificação", o "microlearning" e o "problem based learning" são também subcategorias da categoria "Novas Metodologias" demonstrando de igual forma maturidade destas num contexto muito mais de mudança decorrente da indústria 4.0 do que da situação de pandemia.

No entanto, a sugestão de Moreira et al. (2020), de um paradigma de educação mais híbrido, de maior convergência entre realidades biológicas e físicas com realidades digitais e virtuais, a Educação Digital, configurando-se naquilo que neste artigo designamos por território ciberfísico, deve igualmente ser aplicado à Formação Profissional. Este paradigma justifica-se não apenas e não tanto pela situação de pandemia, mas principalmente tendo em conta as transformações decorrentes da $4 .^{a}$ Revolução Industrial, acrescidas da distribuição desigual da tipologia de indústrias pelos distritos nacionais e o grande número de micro indústrias com menos de 10 trabalhadores/as. 
83 As inovações associadas à indústria 4.0 serão uma oportunidade para que a formação abandone de uma vez por todas o esquema igual para todos, rígido e hierárquico baseado num modelo industrial de produção em massa, típico da 2. a Revolução Industrial e passar a estar assente num modelo de $4{ }^{a}$ revolução industrial ou similar ao modelo de Educação 4.0. Algo semelhante ao modelo redárquico (Naji, 2018) um modelo de sociedade pós-industrial inspirado nos trabalhos de Richard Sennet e Saskia Sassen que levam a outra visão da nossa sociedade e que surge como resultado das relações de participação e fluxos de atividades gerados em ambientes colaborativos.

84 Este modelo assenta nos seguintes princípios : (i) as pessoas são o centro dos processos e decisões; (ii) o trabalho cognitivo deve ser orientado para a aprendizagem colaborativa; (iii) a participação de todos aqueles que podem contribuir deve ser incentivada ; (iv) o conhecimento, o talento e a criatividade devem ser partilhados ; (v) o conhecimento deve estar disponível a todos aqueles que dele necessitem e ser transparente; (vi) a inovação é entendida como produto das redes de informação e conhecimento na procura de uma solução para problemas comuns; (vii) o envolvimento maior e igual de todos os estratos da organização social promove a aprendizagem ao longo da vida.

Tendo por base este modelo verificamos a importância da formação em Trabalho em Equipa / Colaborativo, Gestão de Pessoas e Inteligência Emocional, que os /as formadores/as indicaram ter recebido no âmbito da indústria 4.0, enquanto simultaneamente compreendemos que a aplicação da aprendizagem hibrida e da aprendizagem adaptativa, uma das categorias emergentes da análise das repostas dos/ as formadores/as ao nosso questionário, passa a ser viabilizada pela aplicação da modalidade de e-learning "permitindo que a aprendizagem ocorra no tempo e lugar mais motivadores para os alunos, no seu próprio ritmo e estilo de aprendizagem" (Naji, 2018, p. 181) e onde a "colaboração", a "criatividade e a "resolução de problemas" surgem como as principais competências a serem adquiridas pelos formandos, o que vai ao encontro dos princípios do modelo redárquico.

\section{Considerações finais}

86 No que diz respeito ao nosso estudo, e tendo em conta as mudanças que a $4 .{ }^{\mathrm{a}}$ revolução industrial está a e vai continuar a produzir, concluímos que a variável território é fundamental no estudo das atividades de trabalho e dos seus protagonistas. Esta variável deve, por isso, constituir-se como uma categoria de análise específica, tendo em conta que a distribuição das indústrias e da força de trabalho que as mantém tem uma distribuição extremamente desigual no território nacional e consequentemente terá também necessidades de aquisição e/ou atualização de competências distintas.

A distribuição distinta no território das indústrias, privilegia os distritos litorais (Porto, Lisboa, Braga, Aveiro, Leiria, Setúbal) sobre os distritos do interior do país com impactos que distintos, nomeadamente no desenvolvimento desigual do país e futuramente nas questões da atualização de competências dos adultos e da formação. Desta distribuição desigual decorrem muitas das diferenças que, reforçadas pelo êxodo rural a partir da segunda metade do século XX, vêm criar acentuadas assimetrias regionais, pela urbanização da região litoral do país, levando à criação das áreas metropolitanas de Lisboa e do Porto em 1991, que são efetivamente aquelas onde há maior concentração de indústrias. Ao mesmo tempo, esta desigual distribuição leva ao 
processo de despovoamento do interior com um declínio demográfico e processos de envelhecimento mais acentuados.

Assim, antevemos desigualdades entre territórios, tendo em conta diferentes níveis de industrialização dos mesmos e por isso, é imperativo pensar as relações entre formação e território e nas implicações destes novos territórios virtuais e globais no mundo do trabalho e no perfil dos/as formadores/as. A dimensão territorial torna-se, assim, uma componente fundamental na análise do campo da formação. Deste modo, à semelhança daquilo que já ocorreu nos anos 70 e 80 no campo da formação profissional e formação e formadores, sugere-se um plano de formação profissional que tenha em conta a distribuição geográfica e de sectores das indústrias pelos distritos, levando consecutivamente a um plano de formação de formadores que contribua para este fim.

Outra questão importante a ter em conta é o facto desta $4 .^{\text {a }}$ revolução industrial afetar as indústrias portuguesas e exigir a aquisição de novos conhecimentos por parte dos/as seus/suas trabalhadores/as e a sua requalificação, com especial enfoque nos distritos mais industrializados onde a formação será mais necessária e deverá existir em maior número. Esta necessidade de aquisição e/ou atualização de competências será também distinta tendo em conta a distribuição desigual de indústrias pelo território nacional. Se pensarmos num possível modelo de Learning Factory (Fábrica de Aprendizagem) como tem vindo a ser implementado na Europa em países como a Alemanha e a Áustria e tivermos em conta que na realidade portuguesa falamos maioritariamente de um tecido industrial composto por micro indústrias, teremos de conhecer detalhadamente o tecido industrial presente em cada distrito. Posteriormente a articulação de uma Learning Factory deverá também ser feita com as instituições de educação e formação presentes em cada distrito.

Esta atualização de competências irá exigir também mais formadores/as, seja presencialmente ou à distância, e necessariamente mais mudanças na sua prática pedagógica, o que vai ao encontro dos dados da nossa investigação. Contudo, verificamos ainda uma percentagem extremamente baixa de conhecimento sobre este novo paradigma tecnológico e industrial e das reais mudanças que este parece trazer para a vida e para a realidade das indústrias portuguesas. Acreditamos, assim, que é necessária uma estratégia concertada entre os vários intervenientes, nomeadamente : indústrias, tecido empresarial e associações empresariais; organismos governativos e de gestão territorial e organizações de educação de adultos e de formação profissional. Esta estratégia deverá permitir que todos os/as intervenientes conheçam o conceito de indústria 4.0 e possam antever algumas das principais mudanças e impactos que esta $4 .{ }^{\mathrm{a}}$ revolução industrial trará à sua atividade profissional, económica, social e pessoal. Deverá ser de particular relevo uma definição de uma estratégia de formação de formadores que dote os/as mesmos/as destes conhecimentos e competências que possam conduzir a reais mudanças nas suas práticas pedagógicas e um alavancar da preparação necessária a uma revolução industrial predita onde as estratégias de inserção da mesma podem ser moldadas pelos países (Hermann, Pentek \& Otto, 2015).

91 É neste sentido que se prevê uma exigência diferente à própria formação de formadores, no sentido de responder aos desafios de formação dos/as próprios/as trabalhadores/as das indústrias, com vista à preparação doas/as mesmas/as para esta 
revolução industrial que se avizinha. A formação de formadores no âmbito da indústria 4.0 deverá dar particular atenção aos seguintes aspetos :

i. As competências necessárias aos/às formandos/as que serão os/as trabalhadores/as afetados/as pela 4. ${ }^{a}$ Revolução Industrial, nomeadamente as competências transversais e digitais, que lhes permitirão atuar num paradigma industrial ainda relativamente desconhecido, com cenário de mudança mais rápida e de consequente e progressiva digitalização.

ii. A utilização da tecnologia nos processos de formação, nomeadamente através do uso de novas tecnologias e novas metodologias de formação, muitas delas decorrentes das evoluções tecnológicas da própria indústria 4.0 e similares aquelas que já acontecem em cenários de Educação 4.0 e de Learning Factories.

iii. A aprendizagem heutagógica (Blaschke, 2012) onde o formando é gestor e figura central do seu próprio processo de aprendizagem e é responsável por ele, levando a figura do formador para um plano mais horizontal e equitativo e mais coincidente com um modelo redárquico.

Deste modo a categoria "território", aqui entendida na realidade portuguesa como distrito fortemente marcada por uma divisão litoral e interior, passa a ser uma categoria de análise determinante para a previsão de um plano de digitalização das indústrias e da atividade formativa dos formadores/as portugueses/as. Assim, sugerimos que o território não seja apenas visto como político-estatal, sendo esta visão contestada pelo conceito de ciberespaço, já que este não possui fronteiras nem limites político-administrativos. Para isso, propomos uma nova categoria de território que decidimos apelidar de território ciberfísico, não apenas porque esta deslocalização de recursos seja possível, mas principalmente porque as transformações da 4. ${ }^{a}$ Revolução Industrial irão permitir que todo o processo seja controlado a partir de qualquer ponto geográfico com pouca ou nenhuma intervenção de trabalhadores/as, que poderão realizar o controlo da produção à distância. Urge por isso, repensar também as tradicionais estruturas de organização social e educativa, na sua forma de organização, objetivos e missão de trabalho, enquanto simultaneamente esta nova forma de encarar o território deve ser incorporada nas estruturas existentes e na sua forma de trabalho atual. Antevemos necessidade de criar novas estruturas de organização social e educativa numa escala global e simultaneamente um processo de colaboração ciberfísico nas estruturas existentes.

Será também fundamental estar ciente de dois impactos inevitáveis, ainda que pouco visíveis: (i) o ciberespaço, enquanto consequência de uma nova tecnologia está profundamente entrelaçado com as relações materiais e sociais pré-existentes, fazendo com que as novas tecnologias reforcem as velhas estruturas sociais, em vez de as transformar (Ekdahl \& Trojer, 2002); (ii) a implementação de novos modelos e/ou metodologias de formação requer experiência (Naji, 2018), algo que ainda parece muito incipiente no país. Qualquer que seja o novo paradigma de formação assente nas tecnologias digitais, este deve estar muito atento a estas questões, para não se tornar num veículo de desigualdades em vez de um promotor de desenvolvimento social e económico.

94 Estamos em crer que caberá ao campo das Ciências da Educação enfrentar estes desafios satisfazendo as necessidades do mundo contemporâneo, repensando as suas linhas orientadoras de modo que os sistemas de educação e formação possam contemplar objetivos mais alargados que os presentes, adotando um paradigma que seja 
consentâneo com a especificidade dos adultos e dos seus processos de aprendizagem e, simultaneamente, com as transformações, desafios e impactos da Indústria 4.0.

Adero, N. \& Juma, J. (2021). The Future of Africa in the Post-COVID-19 World. Inter Region Economic Network (IREN). Affairs 72(1), 37-50.

Almeida, F. (2002). O sistema de formação de formadores. Lisboa: Observatório do Emprego e Formação Profissional.

Bardin, L. (2011). Análise de Conteúdo. Lisboa : Edições 70.

Baudin, C., \& Nusshold, P. (2018). Digitalização e evolução do trabalho real : Introdução. Laboreal, 14(2), 9-14.

Cação, R., \& Dias, P. (2003). Introdução ao e-learning. Sociedade Portuguesa de Inovação : Porto.

Carvalho, R. (2017). Industry 4.0 - Is Portugal prepared for the future? (Tese de Mestrado). Instituto Politécnico de Leiria, Portugal.

Cataia, M. (2011). Território político : Fundamento e fundação do Estado. Sociedade \& Natureza, 23(1), 115-125.

Chin, A., Juhn, C., \& Thompson, P. (2006). Technical Change and the Demand for Skills during the Second Industrial Revolution : Evidence from the Merchant Marine, 18911912. Review of Economics and Statistics, 88(3), 572-578. https://doi.org/10.1162/rest. 88.3.572

Dwivedia, Y., Hughesa, D., Coombsb, C., Constantiouc, J., Duand, Y., Edwardse, J., Guptaf, B., ... Upadhyayla, N. (2020). Impact of COVID-19 pandemic on information management research and practice : Transforming education, work and life. International Journal of Information Management, 55. https://doi.org/10.1016/j.ijinfomgt.2020.102211

Ekdahl, P., \& Trojer, L. (2002). Digital Divide : Catch up for what? Gender, Technology and Development, 6(1), 1-20.

Fontes, C. (2002). A Formação de Formadores em Portugal: Contributo para o estudo dos modelos e práticas de formação institucionais. Lisboa.

Fórum Económico Mundial (2020). Towards a Reskilling Revolution A Future of Jobs for All. Genebra.

107 Greenwood, J. (1999). The third industrial revolution: Technology, productivity, and income inequality. Economic Review, 35(2), 2-12.

Hein, C. (2005). Reconciling work and family responsibilities. Geneva : International Labour Organization. Scenarios : A Literature Review. Working Paper. Kipper, L., Iepsen, S., Dal Frono, A., Frozza, R., Furstenau, L., Agnes, J., \& Cossul, D. (2021). Scientific mapping to identify competencies required by industry 4.0. Technology in Society, 64. https://doi.org/10.1016/j.techsoc.2020.101454 Leduc, S., \& Ponge, L. (2018). La Evolución Digital y los cambios organizativos : Qué respuestas de la Ergonomia? Laboreal, 14(2), 31-44. https://doi.org/10.4000/laboreal. 609

Lévy, P. (1999). Cibercultura. São Paulo : Editora 34. 
113 Lopes, R. (2006). Concepções científicas e pessoais sobre Educação/Formação Profissional: contributos para elaboração de um modelo teórico (Tese de Doutoramento). Universidade do Minho, Portugal.

114 Mokyr, J. (1998). The second industrial revolution, 1870-1914. Storia dell'economia Mondiale, 219-245.

115 Moreira, J., Henriques, S., Barros, D., Goulão, M., \& Caeiro, D. (2020). Educação digital em rede : Princípios para o design pedagógico em tempos de pandemia. Universidade Aberta : Educação à Distância e Elearning.

116 Mrugalska, B., \& Wyrwicka, M. (2017). Towards Lean Production in Industry 4.0. Procedia Engineering, 182, 466-473. https://doi.org/10.1016/j.proeng.2017.03.135

117 Naji, M. (2018). Industria 4.0, competencia digital y el nuevo Sistema de Formación Profesional para el empleo. Revista Internacional y Comparada de Relaciones Laborales y Derecho del Empleo, 6(1), 165-194.

118 Oesterreich, T., \& Teuteberg, F. (2016). Understanding the implications of digitisation and automation in the context of Industry 4.0: A triangulation approach and elements of a research agenda for the construction industry. Computers in Industry, 83, 121-139. http://doi.org/10.1016/j.compind.2016.09.006

119 Oke, A., \& Fernandes, F. (2020). Innovations in Teaching and Learning : Exploring the Perceptions of the Education Sector on the 4th Industrial Revolution (4IR). Journal of Open Innovation, 6(31), 1-22. https://doi.org/10.3390/joitmc6020031

120 Roblek, V., Meško, M., \& Krapež, A. (2016). A Complex View of Industry 4.0. SAGE Open, 1-11. https://doi.org/10.1177/2158244016653987

121 Rodrigues, A. (2019). Formadores de Formadores: Recursos, Guias ou Magos? Um estudo exploratório sobre a(s) identidade(s), perceções e desafios dos profissionais investidos na formação dos seus (futuros) pares (Tese de Mestrado). Universidade do Porto, Portugal.

Spöttl, G., \& Windelband, L. (2021). The 4th industrial revolution-its impact on vocational skills. Journal of Education and Work, 34 (1), 29-52. https://doi.org/ 10.1080/13639080.2020.1858230

Stuart, D. (1998). Digital domains: Nation, state and virtual territory. Paideusis Journal for Interdisciplinary and Cross-Cultural Studies, 1, 114-120.

124 Zhou, K., Liu, T., \& Zhou, L. (2015). Industry 4.0: Towards future industrial opportunities and challenges. In 12th International Conference on Fuzzy Systems and Knowledge Discovery (FSKD). https://doi.org/10.1109/FSKD.2015.7382284

[4] Para efeitos de análise neste trabalho optou-se por adotar a escala "distritos" como sinónima de "território" por razões de conveniência, nomeadamente no acesso e consulta das fontes de dados acedidas estarem assim organizadas e apenas permitirem esta categorização de dados por referência a essa unidade geográfica. Não obstante, reconhece-se que uma análise mais fina poderia destacar a diferenciação interna dos distritos enquanto territórios em termos do seu posicionamento face às variáveis consideradas. 


\section{NOTAS}

1. Optámos por incluir as regiões Autónomas dos Açores e da Madeira nesta análise e comprara cada um destas regiões como se fosse um distrito.

2. Para efeitos de análise neste trabalho optou-se por adotar a escala "distritos" como sinónima de "território" por razões de conveniência, nomeadamente no acesso e consulta das fontes de dados acedidas estarem assim organizadas e apenas permitirem esta categorização de dados por referência a essa unidade geográfica. Não obstante, reconhece-se que uma análise mais fina poderia destacar a diferenciação interna dos distritos enquanto territórios em termos do seu posicionamento face às variáveis consideradas.

3. Este projeto de doutoramento foi financiado pela Fundação Ciência e Tecnologia (FCT) com a referência PD/BD/135470/2017.

4. 0 distrito de Aveiro embora apareça nos critérios de análise "N. de indústrias" e "Exercício de atividades de formador/a", é substituído por Coimbra no critério "Mudanças na prática pedagógica" e por Setúbal no critério "Especificação das mudanças na prática pedagógica”, como se pode ver na Tabela 6. Posicionamento do território (distrito) face a critérios de análise.

\section{RESUMOS}

As mudanças decorrentes dos recentes avanços tecnológicos, no âmbito da indústria 4.0, impulsionadas quer pelo rápido desenvolvimento das TIC, quer pela pandemia de COVID-19 que, entre outros, levou a que uma parte substancial da população vivesse numa situação de teletrabalho, levam-nos a refletir sobre o possível impacto destas mudanças no mundo do trabalho e no exercício da atividade de formador/a. A partir da análise do contexto industrial português e de 1.586 respostas de formadores/as nacionais a um inquérito por questionário, recolhidas entre dezembro de 2020 e abril de 2021, procurámos auscultar as suas perceções sobre as principais mudanças na sua função profissional decorrentes principalmente da $4 .^{\text {a }}$ revolução industrial (i4.0). Conclui-se que há uma distribuição desigual das indústrias pelo território nacional, o que poderá explicar impactos desiguais no mundo do trabalho e respetivas diferenças nas práticas de formação que podem, no entanto, ser mitigadas através do uso das tecnologias inerentes e decorrentes da própria indústria 4.0.

Los cambios resultantes de los recientes avances tecnológicos en el contexto de la industria 4.0, impulsados ya sea por el rápido desarrollo de las TIC o por la pandemia COVID-19, que, entre otros, llevó a que una parte sustancial de la población viviera en una situación de teletrabajo, nos llevan a reflexionar sobre el posible impacto de estos cambios en el ejercicio de la actividad de formador/a. A partir del análisis del contexto industrial portugués y de 1586 respuestas de formadores nacionales a un cuestionario, recopiladas entre diciembre de 2020 y abril de 2021, buscamos escuchar sus percepciones sobre los principales cambios en el mundo del trabajo y en su rol profesional procedentes principalmente de la $4^{\text {a }}$ revolución industrial (i4.0). Se concluye que existe una distribución desigual de las industrias en el territorio nacional, lo que puede explicar los impactos desiguales en el mundo del trabajo y sus respectivas diferencias en las 
prácticas de formación que, sin embargo, pueden ser mitigadas mediante el uso de tecnologías inherentes derivadas de la propia industria 4.0.

Les changements résultant des récentes avancées technologiques, dans le contexte de l'industrie 4.0, incitées par le développement rapide des TIC mais aussi par la pandémie de COVID-19 qui a, notamment, conduit une partie substantielle de la population à vivre en situation de télétravail, nous amènent de réfléchir sur l'impact possible de ces changements dans l'exercice de l'activité de formateur/trice. À partir de l'analyse du contexte industriel portugais et sur la base des 1.586 réponses à une enquête nationale réalisée par questionnaire auprès de formateurs, recueillis entre décembre 2020 et avril 2021, nous avons cherché à discerner leurs perceptions des principaux changements survenus dans leur fonction professionnelle qui résulteraient principalement de la $4 \mathrm{e}$ révolution industrielle (i4.0). Il en est conclu que la répartition inégale des industries sur le territoire national peut expliquer les impacts diversifiés sur le plan du travail et des pratiques de formation - différences toutefois susceptibles d'être atténuées par l'utilisation de technologies issues de l'industrie 4.0 elle-même.

The changes resulting from recent technological advances, in the context of industry 4.0, driven either by the rapid development of ICTs or by the COVID-19 pandemic, which, among others consequences led to a substantial part of the population living in a situation of teleworking, made us reflect on the possible impact of these changes in the trainers' activities. Based on the analysis of the Portuguese industrial context and a national survey, administered between December 2020 and April 2021, answered by 1.586 trainers, we sought to listen to their perceptions about the main changes in the world of work and in their professional role arising mainly from the 4th industrial revolution (i4.0). It is concluded that there is an unequal distribution of industries across national territory, which may explain differences in training practices that can, however, be mitigated through the use of inherent technologies arising from the 4.0 industry itself.

ÍNDICE

Keywords: industry 4.0, digitization, distance learning, cyberphysical territory, training of trainers

Mots-clés: industrie 4.0, numérisation, formation à distance, territoire cyberphysique, formation de formateurs

Palavras-chave: indústria 4.0, digitalização, formação à distância, território ciberfísico, formação de formadores

Palabras claves: industria 4.0, digitalización, formación a aistancia, territorio ciberfísico, formación de formadores

\section{AUTORES}

\section{ANA I. AZEVEDO}

https://orcid.org/0000-0002-8559-3778

Centro de Investigação e Intervenção Educativas ; Faculdade de Psicologia e de Ciências da Educação da Universidade do Porto, R. Alfredo Allen, 4200-135 Porto, Portugal

anisabelsousa@gmail.com 


\section{JOÃO CARAMELO}

https://orcid.org/0000-0002-8345-3915

Centro de Investigação e Intervenção Educativas ; Faculdade de Psicologia e de Ciências da Educação da Universidade do Porto, R. Alfredo Allen, 4200-135 Porto, Portugal

caramelo@fpce.up.pt

\section{SOFIA MARQUES DA SILVA}

https://orcid.org/0000-0002-2688-1171

Centro de Investigação e Intervenção Educativas ; Faculdade de Psicologia e de Ciências da Educação da Universidade do Porto, R. Alfredo Allen, 4200-135 Porto, Portugal

sofiamsilva@fpce.up.pt 